\title{
Dense ceramics with complex shape fabricated by 3D printing: A review
}

\author{
Zhe $\mathrm{CHEN}^{a}$, Xiaohong $\mathrm{SUN}^{a, *}$, Yunpeng SHANG ${ }^{a, b}, \mathrm{Kunzhou} \mathrm{XIONG}^{a, b}$, \\ Zhongkai $\mathrm{XU}^{a}$, Ruisong $\mathrm{GUO}^{a}$, Shu $\mathrm{CAI}^{a}$, Chunming $\mathrm{ZHENG}^{b, *}$ \\ ${ }^{a}$ School of Materials Science and Engineering, Key Laboratory of Advanced Ceramics and Machining Technology \\ of Ministry of Education, Tianjin University, Tianjin 300072, China \\ ${ }^{b}$ School of Chemistry and Chemical Engineering, State Key Laboratory of Hollow-fiber Membrane Materials and \\ Membrane Processes, Tiangong University, Tianjin 300387, China
}

Received: July 1, 2020; Revised: December 7, 2020; Accepted: December 14, 2020

(C) The Author(s) 2020.

\begin{abstract}
Three-dimensional (3D) printing technology is becoming a promising method for fabricating highly complex ceramics owing to the arbitrary design and the infinite combination of materials. Insufficient density is one of the main problems with 3D printed ceramics, but concentrated descriptions of making dense ceramics are scarce. This review specifically introduces the principles of the four 3D printing technologies and focuses on the parameters of each technology that affect the densification of 3D printed ceramics, such as the performance of raw materials and the interaction between energy and materials. The technical challenges and suggestions about how to achieve higher ceramic density are presented subsequently. The goal of the presented work is to comprehend the roles of critical parameters in the subsequent $3 \mathrm{D}$ printing process to prepare dense ceramics that can meet the practical applications.
\end{abstract}

Keywords: 3D printing; dense ceramics; particle characteristics; process parameters

\section{Introduction}

As one group of materials that are widely used in industries, ceramics have several characteristics like high hardness, superior strength, excellent hightemperature resistance, and outstanding wear resistance [1]. Unfortunately, it is these characteristics that make ceramics of complex shapes difficult to fabricate with conventional methods including dry pressing, injection molding, roll forming, and tape casting. On the one

* Corresponding authors.

E-mail: X. Sun, sunxh@tju.edu.cn

C. Zheng, zhengchunming@tiangong.edu.cn hand, these traditional preparation techniques are relatively complex and time-consuming. On the other hand, it is not allowed to make ceramic parts with complex shapes, such as curved shapes or honeycomb structures. Besides, ceramic applications in modern production are subjected to many limitations because mold design and manufacturing, which has been widely used in ceramic industries, usually take a very long time. Therefore, there is an urgent need to find new technology to manufacture high-performance ceramics with complex shapes. The concept of additive manufacturing (AM) first appeared in 1892 and originated from a patented technology for making three-dimensional map models using a lamination 
method in the United States [2]. 3D printing is a technique of rapid fabricating complex- shaped objects whereby 3D objects are built by depositing feedstock materials on each layer. With the growth of market demand and technological development, 3D printing is widely used in construction [3], medicine [4], aerospace [5], and other fields [6]. In 2014, WinSun company printed out a large residence in one day, reducing construction time and labor costs [7]. Both in fundamental researches and practical applications, selective laser sintering (SLS), selective laser melting (SLM), stereolithography (SLA) as well as direct inkjet writing (DIW) are the most studied methods of AM that have been widely used in industries so far.

Many studies [8,9] confirm that $3 \mathrm{D}$ printing is extremely ideal for preparing complex structures, such as the commonly used hole structure. However, the porous ceramics prepared by this method often have great deficiencies in terms of ceramic density $[10,11]$. Data from several studies [12-14] show that the applications of 3D printed ceramics are often limited by their low density causing insufficient mechanical properties. In addition to affecting the mechanical properties of ceramics, the density of printed ceramics has a decisive effect on the functions of ceramics. It is worth noting that so far 3D printing technology has been used in the manufacture of functional ceramic devices such as piezoelectric ceramics and solid oxide fuel cells (SOFC), which has been widely studied in the energy field. At present, most of the 3D printing processes on the market that add binders or organic monomers are difficult to bypass the step of debinding or degreasing, which tends to reduce the density of the ceramic green body, because most of the binder or organic monomer will be discharged, leaving only the loose ceramic powder. Therefore, the densification process of $3 \mathrm{D}$ printed ceramics is mainly achieved during high-temperature sintering. There is a good correlation between the density of sintered ceramics and mechanical properties. Within a certain sintering temperature range, although the grains gradually grow, no obvious cracks are produced. At this time, the gradually increasing density leads to an increase in compressive strength, hardness, and elastic modulus. As the temperature continues to rise, the excessive growth of ceramic grains can lead to cracks. Due to crack propagation, the mechanical properties, including bending strength and modulus, will decrease sharply [15]. Strictly speaking, 3D printing is only one of the many steps in the preparation of ceramic devices. The performance of the final parts also depends on the formulation, sintering, and processing.

The main objective of this review is to summarize the latest research advances in the realms of 3D printing technology for its possibility to fabricate high-density ceramics. The review offers important insights into the 3D printing mechanism and its technology for manufacturing highly dense ceramics. Especially, understanding the parameters that can affect the density of final products in different processes will conduce to the fabrication of ceramics with remarkable property. It also provides a comprehensive reference for researchers engaging in $3 \mathrm{D}$ printed ceramics.

\section{Selective laser sintering}

Selective laser sintering (SLS), invented by Carl Deckard et al. in 1986 [16], is a 3D printing preparation approach using powder, in which three-dimensional parts are fabricated by sintering part of powder in a layered manner by means of a laser beam radiation. The SLS process is schematically illustrated in Fig. 1 [17]. In this process, a roller is first used to spread evenly powder materials on the entire bed, and then the laser beam moves on the powder bed at a certain scanning speed controlled. The laser beam interacts with the powder to generate high temperature quickly to achieve sintering. Once the sintering of the first layer is over, the working table is descended by one layer and the rotating roller deposits the second layer of powder onto the previous layer surface. By repeating the process of spreading and sintering the powder, it

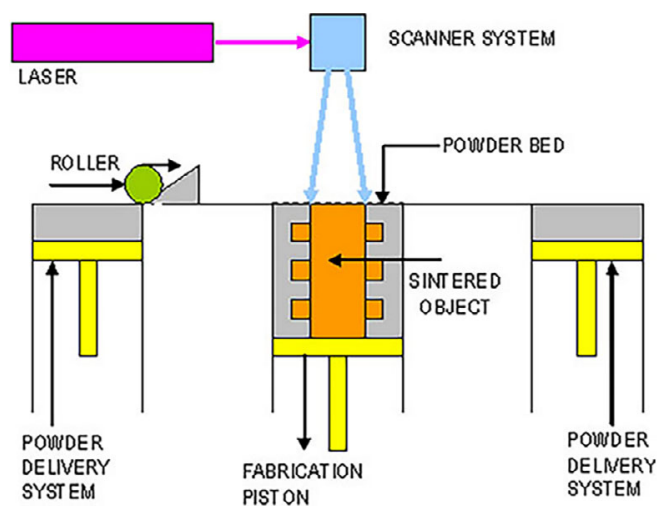

Fig. 1 Schematic representation of SLS preparation process (reproduced with permission from Ref. [17], C) International Federation for Medical and Biological Engineering 2012) 
forms the final part. Preheating the powder bed before SLS can reduce thermal stress to prevent cracks of the sintered part during forming and sintering [18]. Here, the extra powder during the construction process is used to ensure that the parts are supported with no additional support materials. Recent researches [19,20] showed that SLS has tremendous advantages in direct forming complex-shaped ceramics. Figure 2 shows some ceramic parts with complex structures manufactured using SLS. Unfortunately, these ceramic parts rarely have sufficient density after sintering, and the maximum is only $50 \%$ of the theoretical density, which is prone to fracture [21]. This low-density ceramic parts limit its large-scale application in wear-resistant or corrosionresistant fields, such as aerospace ceramic bearings, ceramic cores, or ceramic seals. The strength and toughness cannot meet the actual requirements, which limits applications. At present, ceramics by SLS comprises the direct SLS and the indirect SLS. As we all know, ceramic sintering is mainly a solid-state diffusion process. In the process of using SLS to directly sinter ceramic powder to prepare ceramics, the ceramic powder particles are usually too late to be rearranged and densified within a very short laser action time on account of its extremely high melting point. After SLS, the highly concentrated energy source disappears very quickly and a large thermal stress inside the sintered ceramic part is created because of its poor acute thermal shock. As a result, cracks are inevitably generated in parts directly manufactured by SLS, showing a fairly low density and poor mechanical properties. Compared with direct SLS, the indirect SLS process may be a choice for realizing full densification. The indirect SLS melts and bonds the ceramic powder by laser beam sintering the low-melting polymer binder in the composite, followed by slow heating to remove the unnecessary binder and subsequent reasonable sintering system to increase the final ceramic density [22]. The following sections will only describe the indirect SLS and factors affecting the final density of ceramics.

The geometry and the mean particle size of the powder are critical for achieving powder flowability required for the indirect SLS [24]. Compared to granular particles, the irregular particles may significantly reduce the powder's flowability because of uneven initial packing of the deposited powder [25]. As for the particle size, too small particles also often exhibit poor flowability as a result of a tendency to agglomeration [26]. According to previous reports $[27,28]$, poorly flowing powder surely causes inhomogeneous compactions resulting in sample distortion and low density. So to increase the flowability, the powder should have a spherical shape, suitable grain size distribution consisting of particles with particular three or four sizes and particular corresponding contents [29]. Pfeiffer et al. [30] found that spherical particles are very beneficial to indirect SLS because they ensure a
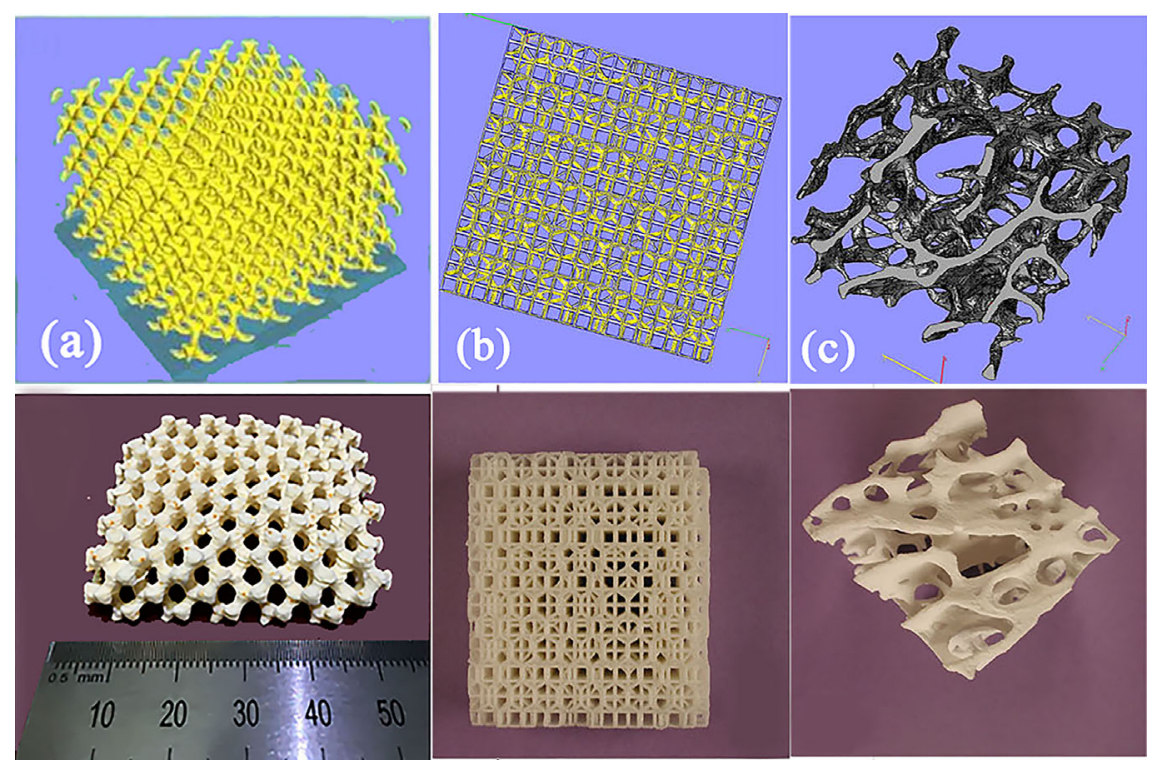

Fig. 2 CAD models (up) and corresponding ceramics made by SLS (down): (a) spiral icosahedral unit topology [23], (b) periodical structure of polygon overlay, and (c) trabecular microstructure (reproduced with permission from Ref. [17], (C) International Federation for Medical and Biological Engineering 2012). 
high flowability of the powder. Considering the influences of particle size on sintered ceramics, Zou et al. [31] elaborated the relationship between the density and particle size of alumina ceramics fabricated by indirect SLS. Among them, when the median diameter $D_{50}$ of $\mathrm{Al}_{2} \mathrm{O}_{3}$ raw material is $22.38 \mu \mathrm{m}$, its packing density is the largest, which is $0.623 \mathrm{~g} / \mathrm{cm}^{3}$. When $D_{50}$ is 112.80 and $5.18 \mu \mathrm{m}$, the packing density of the alumina powder is relatively low. In the preparation process, mixed powder with different particle sizes is used to obtain alumina ceramics. As the proportion of small particles in various powder gradually decreases, the forming density of the SLSed green body is reduced from 2.06 to $1.96 \mathrm{~g} / \mathrm{cm}^{3}$. The compressive strength and flexural strength of the sintered also decreased. In addition, the powder densification during the indirect SLS process can be achieved by liquid phase sintering. The liquid phase is formed by combining a low-melting-point binder with ceramic particles. During sintering, the binder becomes a liquid phase and connects the nearby solid particles together, forming a firm body. Therefore, the connectivity between or among particles is critical to the indirect SLS process. Hao et al. [32] prepared composite materials composed of hydroxyapatite (HA) and polyethylene (HDPE) by indirect SLS process using mixed powder with different particle size distributions. Studies [33-35] have shown that liquid phase sintering is the main powder sintering mechanism in the indirect SLS process and the primary strength of this mechanism is the quick initial combination based on capillary action. The binder phase with a lower melting temperature is melted by the laser radiation and combined with the solid ceramic powder to sinter the powder to form a liquid phase. Figure 3 shows the contact of powder of the composite HA-HDPE during the indirect SLS. The laser melted the surface layer of HDPE to connect the particles of HA first, and then the surface tension on the HDPE surface liquid layer drew the particles together. The capillary force inversely correlates to the radius of curvature [36], while the latter is directly proportional to the grain size [37]. During the sintering of ceramic particles, the densification process is driven by a capillary force inversely related to particle size. The smaller initial particles cause more contact points and a smaller radius of curvature for the larger surface area, and therefore have a stronger binding tendency during the liquid phase sintering [38]. Due to the high porosity and low density, even a small

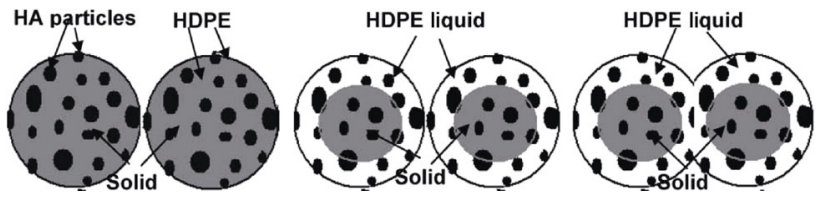

Fig. 3 Formation of inter-particle connectivity during the indirect SLS process (reproduced with permission from Ref. [32], (C) SAGE Publications 2006).

force applied to the printed ceramic parts can cause fracture. Therefore, the parts manufactured by SLS without post-processing can only be used in nonweight-bearing or low-load-bearing applications, such as the facial area, where the growth of bones will improve the mechanical properties and withstand greater forces.

The density of ceramics not only involves the characteristics of the ceramic powder itself but also has a great relationship with the processing parameters. For the indirect SLS, the processing parameters contain laser power, scanning spacing, scanning velocity, and preheating temperature, all of which have been extensively studied [39]. A previous report [40] indicates that laser energy density that determines the energy input acting on powder is one of the most important parameters. It shows the formula for determining the laser energy density in Eq. (1):

$$
q=\frac{P}{H \cdot V}
$$

where $q$ is the laser energy density, $H$ is the scanning spacing, $V$ is the scan speed, and $P$ is the laser power. Fu et al. [41] analyzed the relative influence of these factors on the density of the SLS-formed ceramics through orthogonal experiments and range method. Their experimental results are given in Table 1 .

It is found from the table that the laser power and the scanning spacing have a significant impact on the density, but the enhancement effect of the scan speed is not prominent. The melting amount of the binder can be controlled by producing appropriate energy density generated by high laser power to ensure that the binder flows and adheres to much ceramic powder as possible. Here, since more powder is subjected to liquid surface tension, it will undoubtedly promote densification. However, excessive energy density may cause polymer binder to evaporate or even burn out and thus lose their bonding effect. On the contrary, when the heat generated by the laser is not enough to melt the adhesive, capillary force cannot be formed between the particles because the particles are not sufficiently wetted, which 
Table 1 Orthogonal experimental results of indirect SLS (up) and average density and range of alumina parts at each level (down) [41]

\begin{tabular}{ccccc}
\hline $\begin{array}{c}\text { Laser power } \\
P(\mathrm{~W})\end{array}$ & $\begin{array}{c}\text { Scanning } \\
\text { spacing } v \\
(\mathrm{~mm} / \mathrm{s})\end{array}$ & $\begin{array}{c}\text { Scanning } \\
\text { speed } H(\mu \mathrm{m})\end{array}$ & $\begin{array}{c}\text { Relative } \\
\text { density }(\%)\end{array}$ & $\begin{array}{c}\text { Laser energy } \\
\text { density } \\
\left(\mathrm{J} / \mathrm{mm}^{2}\right)\end{array}$ \\
\hline 7 & 1800 & 100 & 30.2 & 0.038 \\
8 & 2000 & 100 & 31.9 & 0.040 \\
9 & 2200 & 100 & 31.7 & 0.040 \\
8 & 1800 & 150 & 28.7 & 0.029 \\
9 & 2000 & 150 & 28.8 & 0.030 \\
7 & 2200 & 150 & 28.1 & 0.021 \\
9 & 1800 & 200 & 27.5 & 0.025 \\
7 & 2000 & 200 & 27.3 & 0.018 \\
8 & 2200 & 200 & 27.7 & 0.018 \\
\hline \hline & & & & Range \\
\hline$(\mathrm{mm} / \mathrm{s})$ & 28.8 & 29.3 & 29.2 & 0.500 \\
\hline$(\mathrm{W})$ & 28.5 & 29.4 & 29.3 & 0.900 \\
\hline
\end{tabular}

makes it difficult to bond the powder together, resulting in an insufficient density of the ceramic green body [42]. Therefore, the laser power should be slightly above the threshold, so that the powder in the scanning area can be bonded, while the powder out of the scanning area cannot be bonded [43]. Similarly, scanning space will also directly affect the density of ceramics. As the scanning spacing becomes wider and the temperature overlap field becomes narrower, the powder bonding in each sintered layer is no longer continuous, resulting in insufficient green strength [44]. The relative density gradually decreases with increasing scanning speed. Obviously it is because that the high laser scanning speed can only apply less energy to the material, which makes it impossible to bond the ceramic powder [45]. The scanning speed determines how long the laser beam stays on the ceramic powder at the same laser power. The slower the scanning speed, the longer the laser beam heats the powder, thus transferring more heat. The larger relative density is often yielded in large amounts of molten binder. However, at very slow scanning speed, as the interaction of a laser beam over a limited area of powder prolongs, the temperature rises further resulting in excessive sintering, which forms unstable keyhole causing unstable molten powder and trapped air bubbles [46]. Tang et al. [47] prepared high-performance alumina ceramics using orthogonal experiments. After optimizing the parameters, they obtained a set of optimal conditions. With the most suitable laser power $2.0 \mathrm{~W}$ and scanning velocity $870 \mathrm{~mm} / \mathrm{s}$, the alumina ceramic sample has a bending strength of $363.5 \mathrm{MPa}$ and a calculated relative mean density of $98 \%$ (Fig. 4).

Although extensive work has been carried out to make dense ceramics through the indirect SLS process, the process still cannot completely solve the problems of high porosity and heterogeneity of the sintered bodies causing relatively low density, which limits applications requiring high mechanical properties $[19,48]$. To fabricate structurally sound ceramic parts with homogeneity and desirable density, some post processing methods, such as isostatic press (IP), laser remelting, and infiltration at distinctive air pressures should be considered [49]. Liu et al. [50] brought innovatively cold isostatic pressing (CIP) technology into indirect SLS to manufacture high dense ceramic parts. Figure 5 displays the great potential of CIP in manufacturing high-density ceramics after the indirect SLS. Liu et al. [51] combined SLS and CIP using kaolin powder and epoxy resin to obtain crack-free kaolin ceramics. Moreover, a high density of ceramics can be achieved by enlarging the laser energy density during remelting (by rising the laser power or reducing the scan speed). Deckers et al. [52] found that the most effective way to sufficiently densify ceramics is to infiltrate repeatedly the SLS molded body with a stable suspension containing sub-micron $\alpha$-alumina particles under vacuum and then subjected to hot isostatic pressing (HIP). The density of alumina parts after HIP is as high as $88 \%$.

\section{Selective laser melting}

Since the ceramic products obtained by the indirect SLS often have deficiencies of poor sintering and low density, selective laser melting (SLM) technology
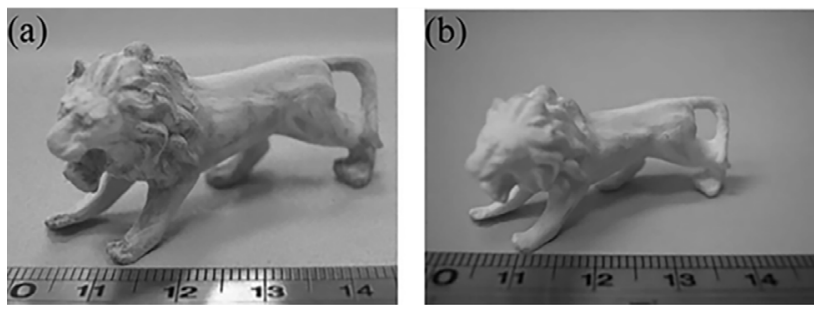

Fig. 4 (a) Indirect SLSed green part, (b) indirect SLSed sintered part (reproduced with permission from Ref. [47], (C) Elsevier Ltd. 2011). 


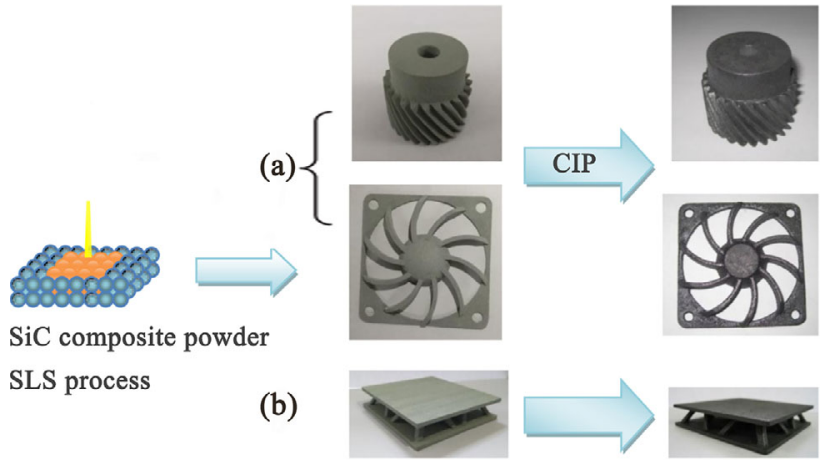

Fig. 5 Complex SiC parts: (a) SLS and CIP combined parts $\left(2.48 \mathrm{~g} / \mathrm{cm}^{3}\right)$, (b) the same processed part without CIP $\left(2.29 \mathrm{~g} / \mathrm{cm}^{3}\right)$ (reproduced with permission from Ref. [53], (C) Elsevier Ltd and Techna Group S.r.l. 2018).

could overcome these deficiencies to a certain extent. A laser source with a much higher power is employed to heat powder during SLM compared to the SLS. Almost dense homogeneous parts with none postprocessing can be theoretically produced as a consequence of the ability to melt powder into a complete liquid phase by the high power laser source. This ensures rapid densification of the entire powder, rather than relying on the melting binder to bond the ceramic powder together like indirect SLS [54]. Figure 6 depicts some alumina ceramic parts manufactured using SLM [55].

As shown in Fig. 7 [56], SLM technology involves a thin, continuous layer of ceramic powder deposited onto the working plate, which is melted by a laser beam with a specific orbit abiding by computer-aided design (CAD) data. During the laser beam scanning, where the laser beam goes, the contact region melts and solidifies rapidly, thereby densifying quickly. After the laser beam selectively scans a layer of powder, the

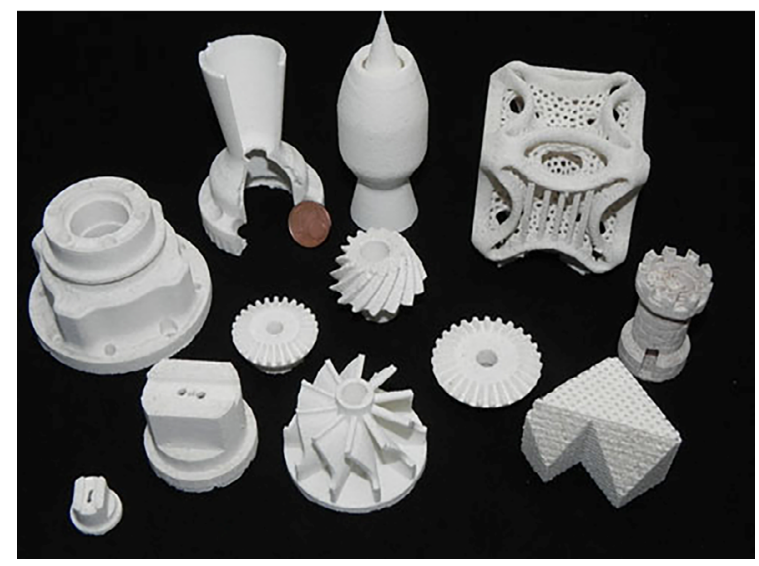

Fig. 6 Pure alumina parts processed by SLM (reproduced with permission from Ref. [55], (C) Materials Research Society 2014).

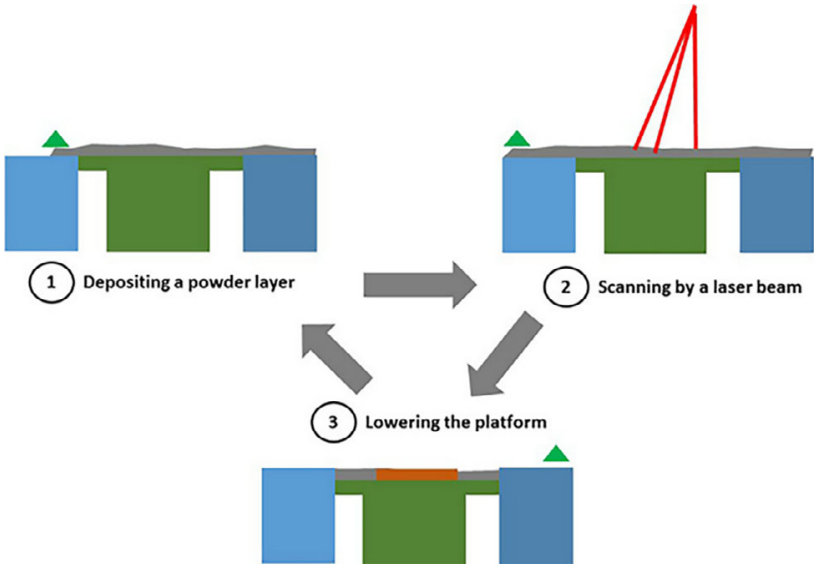

Fig. 7 Schematic representation of the SLM procedure (reproduced with permission from Ref. [56], (C) Emerald Publishing Limited 2017).

laser moves away. The workbench is subsequently lowed, and an additional layer of powder is transferred onto the previous layer to provide new material for a consecutive printing step [57]. It is this technical principle that makes rapid heating and cooling rates possible and inhibits effectively the growth of the recrystallized grain leading to the formation of a refined grain, which is also a key feature of ceramics with excellent properties [58-60]. However, the disadvantage of this technology is that the focused laser with a huge energy density in the SLM may cause large thermal gradients around the laser beam, accompanied by local stresses, leading to the formation of micro-cracks [61].

The entire melting of metal powder has been accomplished in SLM to establish totally dense parts with attractive mechanical properties [62]. It would be expected to achieve similar results for ceramic fabrication. The process parameters of SLM have significant influences on this goal. Generally, these parameters can be categorized into constant parameters and variable nuisance parameters. The constant parameters are those that should be determined and restrained within an appropriate range before processing. The variable nuisance parameters refer to those that are freely chosen to describe laser motion and response to the powder layer during processing [57]. The shape and size distribution of powder are the crucial influential factors affecting powder deposition during SLM. The large friction between particles often derives from irregularity and large size distribution of the particles resulting in poor fluidity and spreadability of the powder [63]. This will be severely detrimental to the 
densification behavior and the resolution of ceramic parts. Smaller-sized spherical ceramic powder is conducive to higher powder bed density and final density. Fateri and Gebhardt [64] used lunar heavy stone simulants to create objects (Fig. 8(a)) through the SLM process. The irregular particles are difficult to disperse throughout the powder bed. The inconsistent volume gaps lead to a heterogeneous mass distribution, which results in voids inside the part. Furthermore, the powder with excessively small particle size not only has a tendency to agglomerate, resulting in poor fluidity but also has a small contact area between particles under loose accumulation, resulting in poor adhesion. Under instantaneous high laser energy, it is easily blown away due to the reaction force [65]. The precision of the prepared nut is in full compliance with the actual application and can be screwed on the screw. In addition to fastening parts, the prepared gears can be used as functional parts in low-stress, high-temperature, or corrosive environments, and are completely suitable for moon landing projects. Wilkes et al. [66] found that the use of spherical powder in the SLM process can significantly reduce porosity (almost $100 \%$ density), which seems to be due to apparently better flowability of the spherical powder than irregular powder (Fig. 9). The obvious flaw is that to further obtain crack-free dense ceramics, high-temperature preheating at $1670{ }^{\circ} \mathrm{C}$ is necessary and therefore generates a large melt pool, expanding the possibility of the ceramic liquid melt

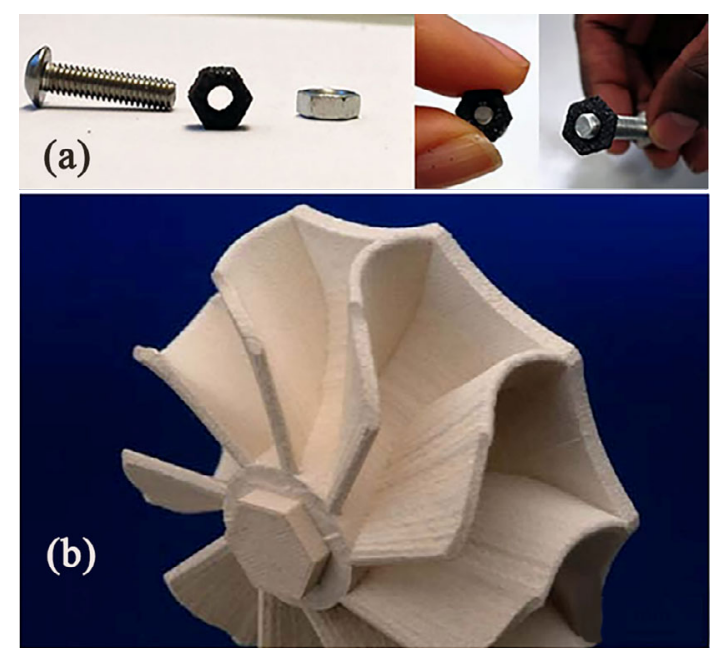

Fig. 8 (a) Nut geometry made by SLM (reproduced with permission from Ref. [64], (C) The American Ceramic Society 2014), (b) part containing $80 \mathrm{wt} \%$ zirconia $/ 20$ $\mathrm{wt} \%$ alumina fabricated using SLM (reproduced with permission from Ref. [66], (C) Emerald Group Publishing Limited 2013).
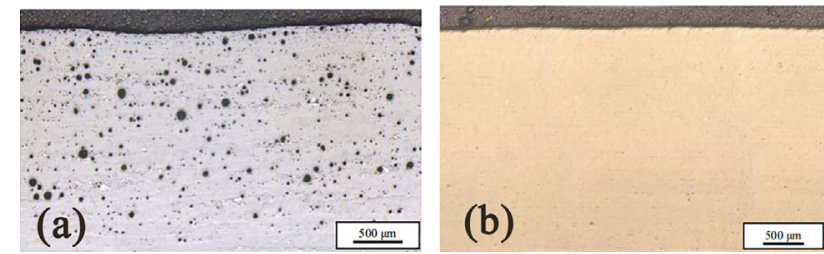

Fig. 9 Cross sections of parts constructed with powder of different shapes: (a) irregular shaped particles, (b) spherical particles (reproduced with permission from Ref. [66], (C) Emerald Group Publishing Limited 2013).

flowing out, which induces a rough surface. A ceramic part fabricated by SLM is presented in Fig. 8(b). As a result of the limited information concerning with performance index applicable to SLM ceramic powder, it is difficult to tell what the best powder state is. Hence, further research in characteristics of powder is needed urgently.

It remains a severe challenge to form ceramics by SLM by reason of the inherent brittleness of ceramics and significantly diverse temperature gradients during processing. While considering the properties of the ceramic powder, optimizing the variable parameters during the processing also facilitates the process [67]. Hence, a proper combination of exposure time, laser power, and scanning velocity is indispensable for SLM to attain fully dense parts [68]. Liu et al. [69] revealed the consequence of exposure time on relative density and microstructure of zirconia ceramics. The noticeable results to emerge from the data are that the relative density significantly varies depending on the extended laser exposure time within the experiment. SEM exhibited quite loose crystal packing at low energy density by cause of short exposure time. When the value of energy density exceeds a certain cutoff, the micro-cracks explode, where the deformation is more pronounced. The maximum relative density of ceramic parts can reach $88 \%$. To maximize density, researchers have further evaluated the role of post-heat treatment (at $1400{ }^{\circ} \mathrm{C}$ for $30 \mathrm{~min}$ ). But it did not work obviously, which decorated that the energy density directly affects the microstructure of ceramics. The same conclusion was also drawn from the work of Zhang et al. [70]. They also found that the roles of laser power and scanning speed cannot be ignored [40,71]. An inversely proportional relationship was noticed between relative density and scanning speed, which should be first ascribed to the discontinuity of printing caused by the existence of pores, as shown in Fig. 10 [72]. For the hand, the scan speed is so fast that the input laser energy 


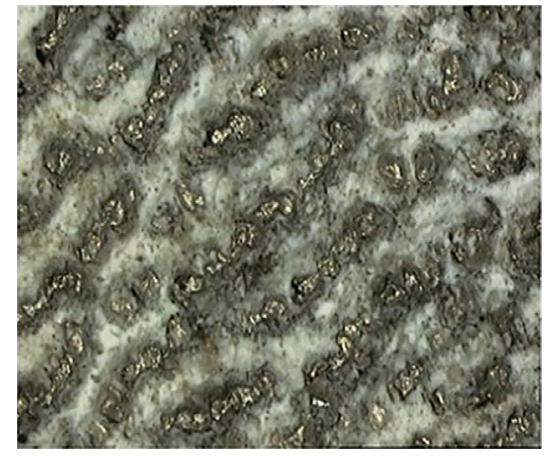

Fig. 10 Discontinuous powder melting between adjacent tracks (reproduced with permission from Ref. [76], (C) the Editorial Council for The Journal of Prosthetic Dentistry 2018).

density is inadequate to thoroughly melt the ceramic powder. When the scanning velocity is constant, as the laser power increases, the small particles first melt to form a liquid phase. At this time, with the help of capillary force and viscous flow, the particles are rearranged into a close compact structure [73]. The higher the laser power, the greater the number of liquid phases produced, and thus the higher the density. However, as the laser power continues to increase, the energy density in the central region will be higher than that in the peripheral area according to the Gaussian distribution [61]. At the same time, the cooling rate in the central area is significantly slower than that in the edge area, which makes solidification take place from the edge and extend to the center area during the cooling process. As shown in Fig. 11, as the volume shrinks, the central area will be subjected to a large tensile force and prone to vertical cracks. Besides, re-crystallization and the eddy current effect in the molten pool in the molten state make the gas unable to be released, thereby reducing the sintering density [74]. High temperature preheating forces the number of cracks to be substantially reduced or even disappeared totally [75], as seen in Fig. 12. Liu et al. [61] insighted into the dependence of relative density on laser power and preheating temperature. The cracks generated on the surface are significantly scaled-down after prewarming at high temperature under low power laser conditions.

\section{Stereolithography}

It is not difficult to find that even if the parameters described above are optimized, the preparation of dense

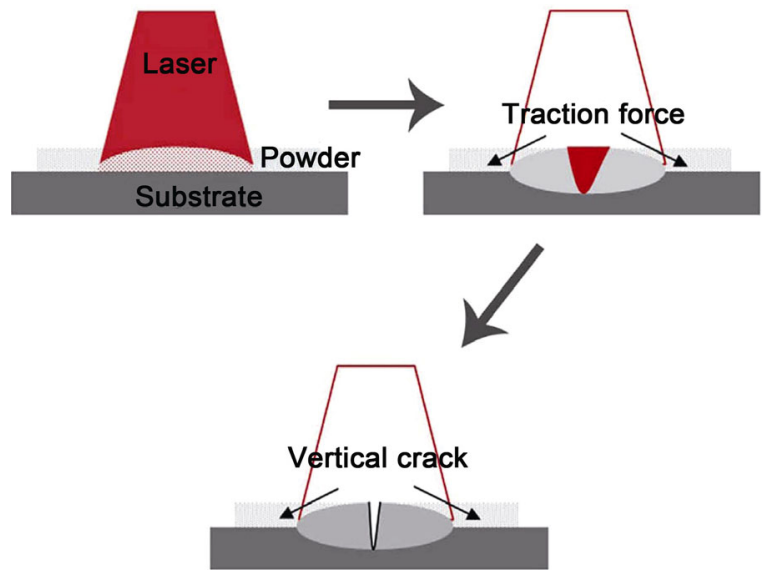

Fig. 11 Procedure for the crack generation during SLM (reproduced with permission from Ref. [61], (C) Elsevier B.V. 2015).
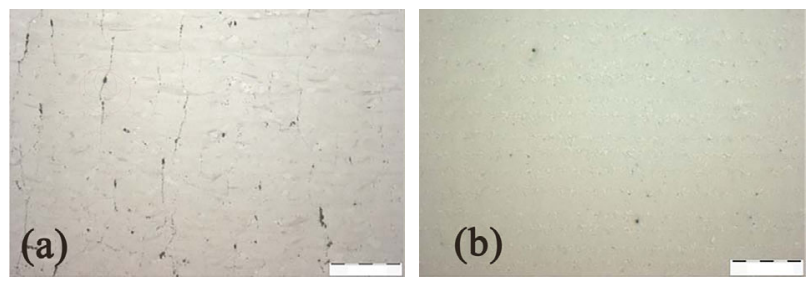

Fig. 12 Cross sections of ceramics without (a) and with (b) preheated SLM (reproduced with permission from Ref. [66], (C) Emerald Group Publishing Limited 2013).

ceramics still requires more post-processing methods to achieve, due to the thermal stress that cannot be completely eliminated in the process. The most fatal flaw lies in the need for grinding and polishing due to poor surface roughness, which will undoubtedly affect production efficiency. Besides, although the hightemperature preheated powder can relieve thermal stress to avoid cracks, the measure often induces poor surface quality and low-resolution accuracy of the printed body parts. Stereolithography (SLA) is considered to be one of the AM technologies that can accomplish ultra-precision manufacturing to date, stemming from its ability to fabricate high-quality objects with resolutions down to the micron level [77, 78]. Figure 13 exhibits a part of ceramic components fabricated by SLA technology [79]. SLA is a change from Charles Hull's method to cure specific areas of polymer resins in the mid 1980s [80]. In short, the crosslinking polymerization of liquid polymers is initiated by a coherent light source in the UV range. The principle of SLA is based on a photopolymerization process that typically exploits some kind of light source to cause the chain reaction of the monomer layer to 
achieve the effect of polymerization. The liquid monomer is converted into a solidified polymer through polymerization of the monomer immediately after activation. After finishing this layer, the build platform descended into the solution to allow the new polymer resin to adhere to the surface of the previous layer and continue to work. When the entire 3D model is printed out, the resin still attached to the parts needs to be removed and the model is usually cleaned with ethanol [81]. In addition, considering the coffee ring effect, ceramic particles tend to deposit around, which disturbs the thickness control of the print and further affects the properties of ceramics. High boiling and high viscosity cosolvent are usually added to the slurry to reduce capillary forces, thereby suppressing this coffee ring effect [82]. It has been well proven from previous studies that the high-density ceramics prepared by SLA are inseparable from a high volume fraction of ceramic particles and a relatively low-viscosity suspension [83]. Therefore, a compromise must be made among the three characteristics (rheology, viscosity, and solid content) to prepare a proper ceramic suspension for the SLA.

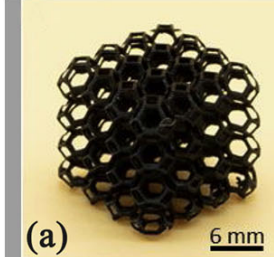

(a)

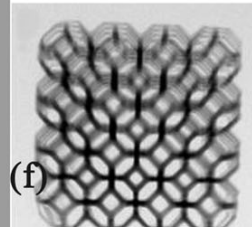

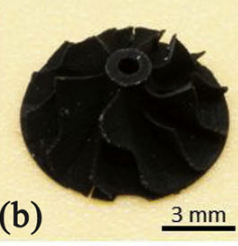

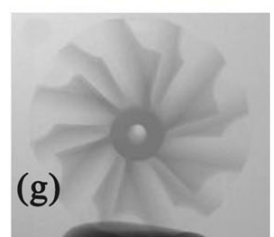

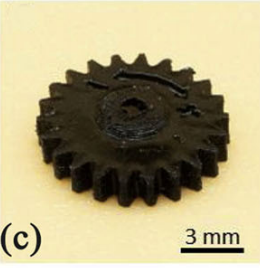

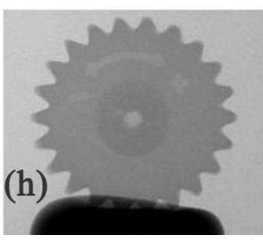

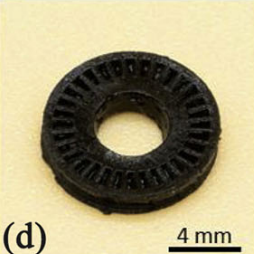

(d)

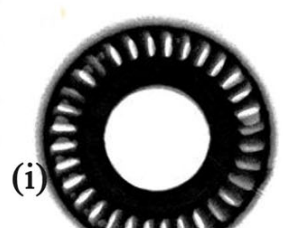

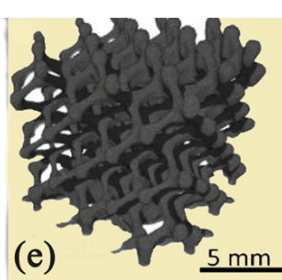

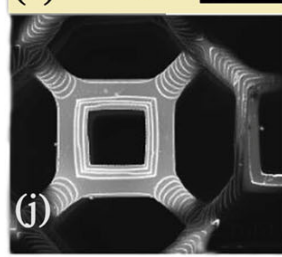

Fig. 13 Several ceramic components fabricated by SLA: (a, b) SiOC with Kelvin cell and turbine impeller structure, (c, d) $\mathrm{SiCN}(\mathrm{O})$ with gear and turbine structure, (e) ceramic with diamond lattice. (f-j) Corresponding radiographs manifest the obtained ceramics are free of macro-defects (reproduced with permission from Ref. [79], C Elsevier B.V. 2019).

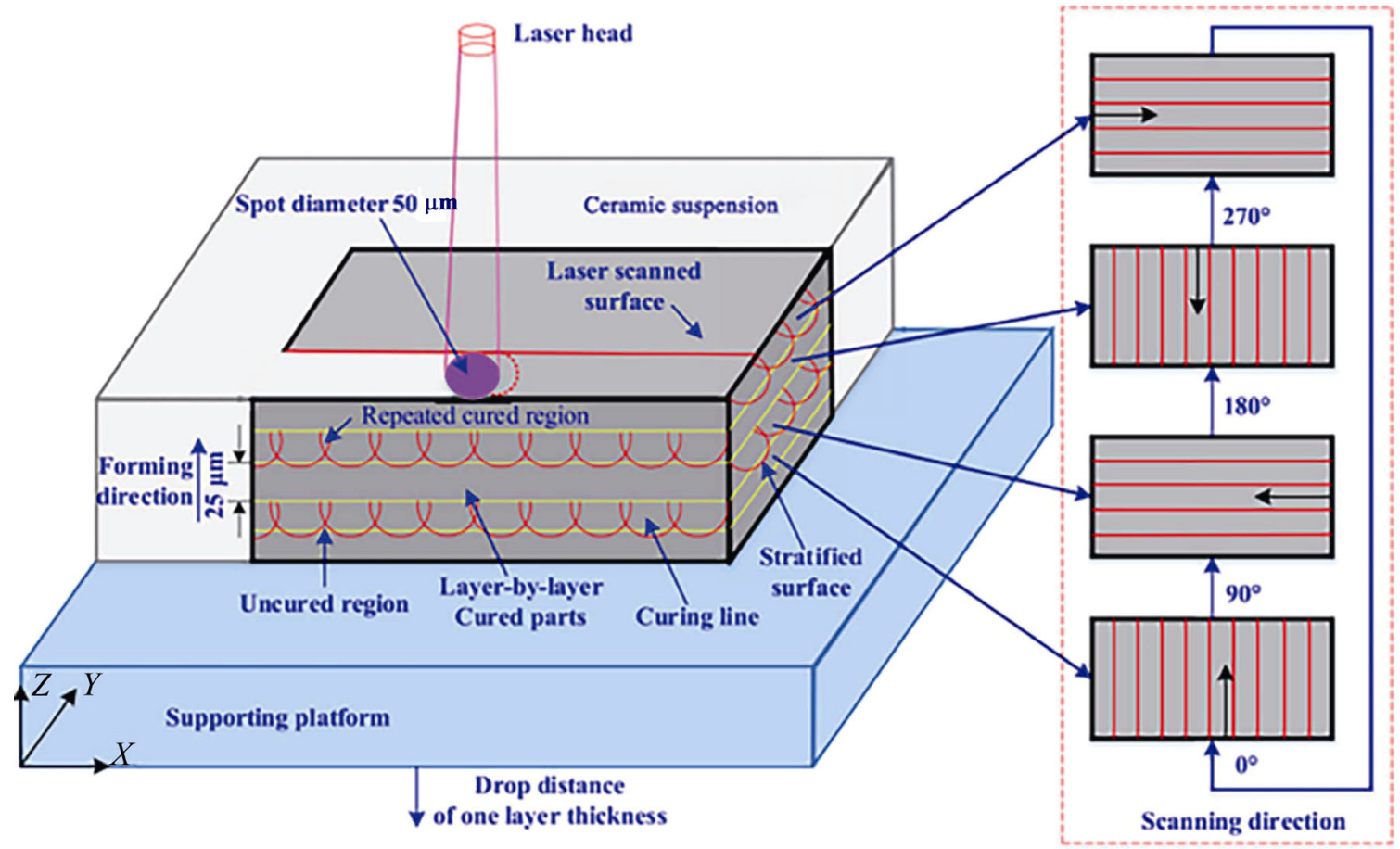

Fig. 14 Preparation path of ceramics in SLA (reproduced with permission from Ref. [84], (C) Elsevier Ltd and Techna Group S.r.l. 2019). 


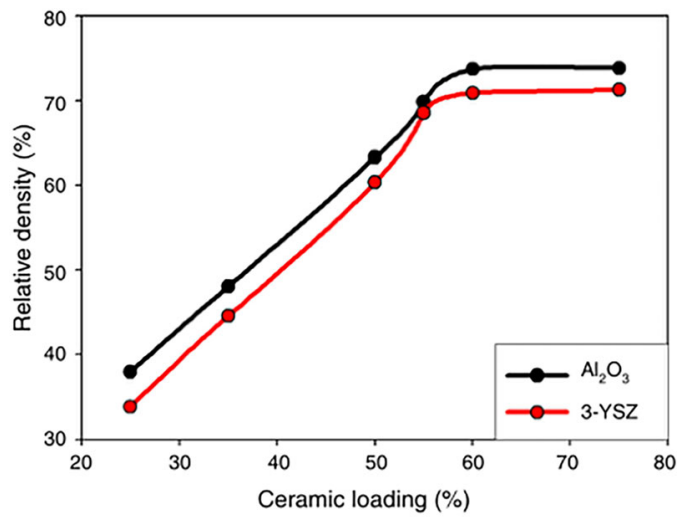

Fig. 15 Relationship between the sintering density of ceramics fabricated by DLP and the ceramic loading (reproduced with permission from Ref. [85], C SECV 2017).

In SLA, the penetration depth $\left(D_{\mathrm{p}}\right)$ of the ceramic suspension is a critical parameter, which is defined as Eq. (2) [86]:

$$
D_{\mathrm{p}}=\frac{2 D_{50}}{3 Q} \frac{n_{0}^{2}}{\left(n_{\mathrm{p}}-n_{0}\right)^{2}}
$$

where $D_{\mathrm{p}}$ is the penetration depth, $Q$ is the scattering coefficient of the slurry, and $\left(n_{\mathrm{p}}-n_{0}\right)$ is the refractive index difference between the ceramic and medium. When the light enters the ceramic slurry, it will be scattered by the ceramic particles. The severe scattering will lead to limited penetration depth and overexposure at the edges of the printed body, thereby affecting dimensional accuracy [87]. In addition, the absorption of light by the powder reduces the light intensity and the penetration depth of the minimum intensity required for curing. Therefore, the curing depth should be equal to the layer thickness plus appropriate over-curing to help the layers bond [88]. Generally, the depth of over-curing should be controlled to $10 \%-35 \%$ of the layer thickness to avoid print-through and delamination [89]. Too much curing depth will make the light penetrate the expected depth resulting in low molding accuracy, while too small curing depth may cause the cured layer to separate and deteriorate the mechanical properties. According to Eq. (2), the penetration depth of the slurry counts mainly on the size of the ceramic particles, dispersion, and solid content. Moreover, the particle size has a vital influence on the properties of the ultimate product. Xing et al. [90] opted the modified $\mathrm{Al}_{2} \mathrm{O}_{3}$ powder with various size distributions to formulate $44.2 \mathrm{vol} \% \mathrm{Al}_{2} \mathrm{O}_{3}$ suspensions with viscosity $<25 \mathrm{~Pa} \cdot \mathrm{s}$ at a shear rate of $30 \mathrm{~s}^{-1}$. High-resolution alumina ceramics without visible deformation were obtained after shaping by SLA technology and subsequent sintering. The density of the objects was up to $99.5 \%$. Generally, ceramic powder with small particle sizes and large volume fractions tends to result in high viscosity and weak fluidity of the ceramic suspension, but such ceramic suspensions usually have excellent stability [91]. Wu et al. [92] fabricated $\mathrm{Al}_{2} \mathrm{O}_{3}$ ceramics using powder with different particle size distributions as raw materials by SLA. Among the three samples with the nano, micro, and mixed $\mathrm{Al}_{2} \mathrm{O}_{3}$ as raw materials, only the product with the particle size distribution of bimodal packing reached a maximum relative density of $91.2 \%$. This can also be confirmed from the microstructure of the three samples (Fig. 16). According to the concept of bimodal powder packing [93], the apt particle size distribution not only raises the volume fraction of the ceramic suspension but also increases the packing density of powder, thus promoting the density of the ceramic body after printing (Fig. 17). Besides, the addition of large particles also decreases the viscosity to some extent, which is beneficial for the printing process. This is also in line with the conclusions drawn from the most researches [94,95]. In other words, compared with the use of single-size particles, grains of variable sizes are more beneficial to increase the density of ceramics prepared by SLA. However, the ceramic suspensions containing particles with too many different sizes often exhibit properties that are not conducive to the printing process, such as low viscosity and poor stability. Therefore, it is necessary to properly adjust the particle size ratio to obtain suspension with suitable viscosity. Song et al. [96] improved the suspension characteristics by optimizing the volume ratio of micro- and nanoparticles of $\mathrm{ZrO}_{2}$ to 3:7. The study showed that as the volume fraction of nanoparticles increases, the penetration depth and the polymerization range of the laser beam are expanded because of excellent stability and weak scattering. It is difficult to observe cracks and voids from the FE-SEM images of the 3D printed $\mathrm{ZrO}_{2}$ (Fig. 18). Once the solid content exceeds the critical point, the viscosity gradually increases, and the relative density decreases as well. This is as the content of particles increases, the distance between particles decreases, resulting in particle collisions and agglomeration. High viscosity reduces fluidity during processing, causing many bubbles at the layer boundary, which results in residual pores after sintering [97]. The final $\mathrm{ZrO}_{2}$ ceramics exhibited small average grain size 

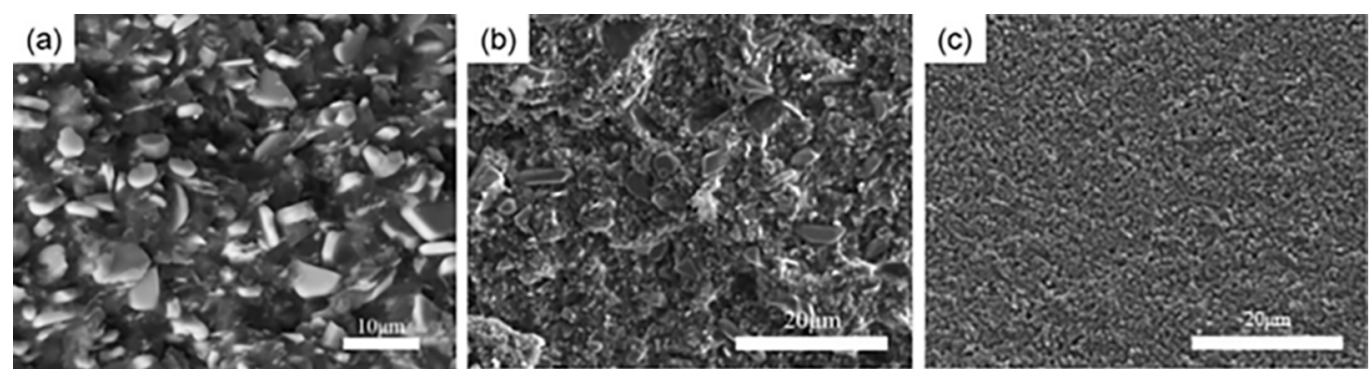

Fig. $16 \mathrm{SEM}$ of the green bodies made of three sizes of powder: (a) micro-scaled $\mathrm{Al}_{2} \mathrm{O}_{3}$, (b) nano-scaled $\mathrm{Al}_{2} \mathrm{O}_{3}$, (c) mixed $\mathrm{Al}_{2} \mathrm{O}_{3}$ (reproduced with permission from Ref. [92], (C) Elsevier Ltd and Techna Group S.r.l. 2016).
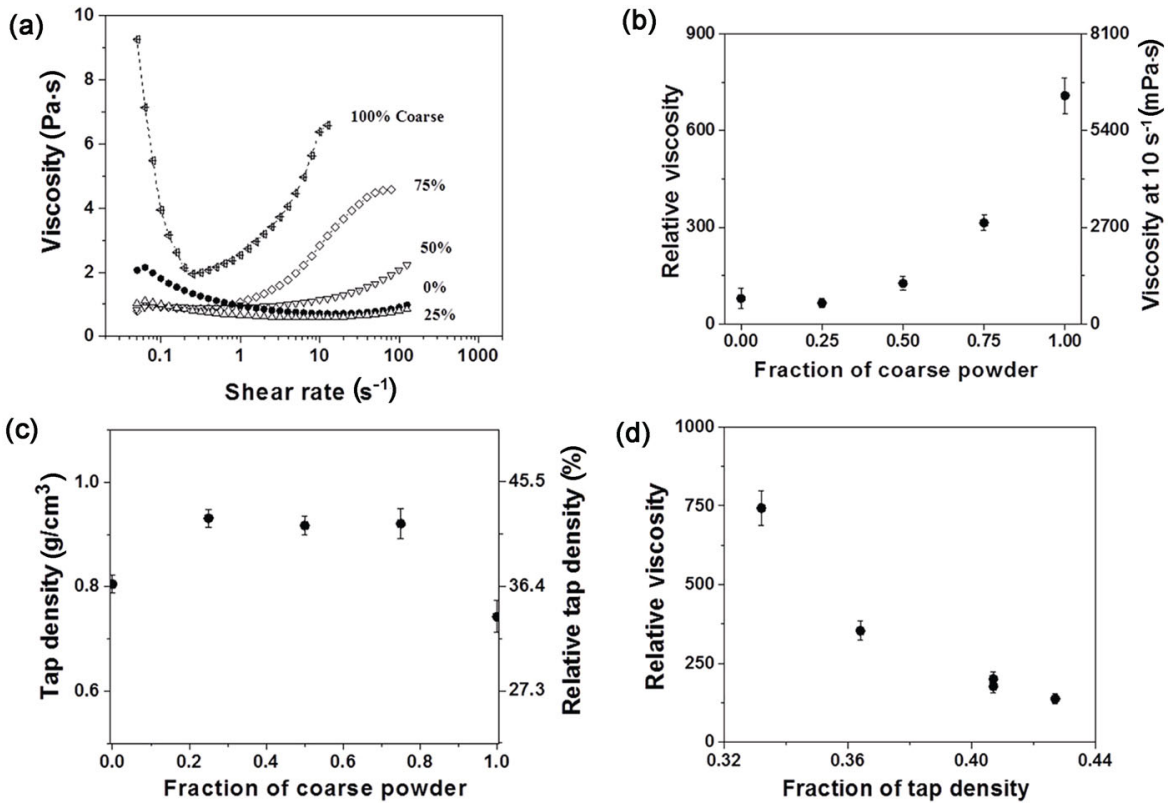

Fig. 17 Viscosity of $\mathrm{SiO}_{2}$ suspension prepared by adding coarse powder and fine powder: (a) relationship between apparent viscosity and shear rate, (b) relative viscosity, (c) tap density as a function of coarse powder content, and (d) relationship between relative viscosity and tap density (reproduced with permission from Ref. [94], (C) Elsevier Ltd. 2019).

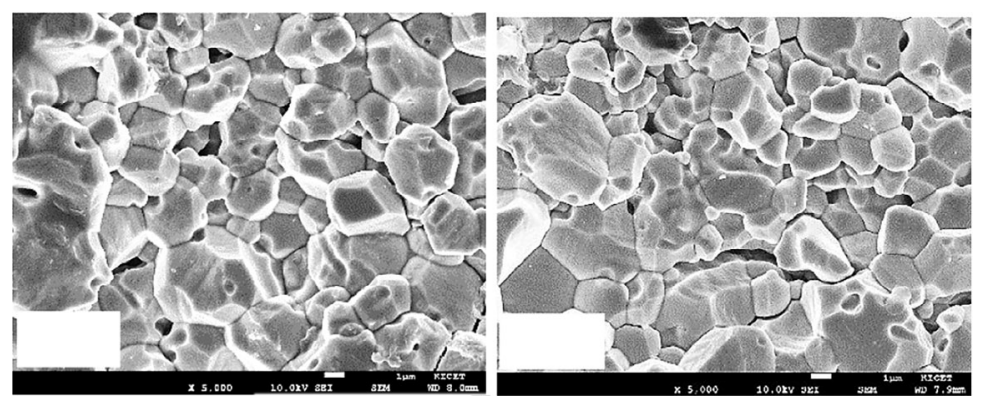

Fig. 18 Cross-sectional images of sintered $\mathrm{ZrO}_{2}$ bodies (reproduced with permission from Ref. [96], (C) The Authors 2019).

$(3.66 \mu \mathrm{m})$ and high relative density $\left(5.61 \mathrm{~g} / \mathrm{cm}^{3}\right)$.

In addition to considering the influences of slurry characterizations on the properties of the subsequent molded parts, the printing strategy also needs to be rationally optimized, including laser power, scanning speed, and printing direction. The study [98] has shown that the solidification depth is not only related to the ceramic powder but also has a certain relationship with the laser parameters. The cured depth is inversely proportional to the speed of the laser movement when the laser power keeps constant. Wang et al. [99] optimized the laser power and scanning speed to improve the properties for $\mathrm{ZrO}_{2}$ ceramic through the Taguchi method [100] that provides an effective method 
to optimize the process by setting design parameters. The results showed that the density is not obviously affected by the laser power and the laser moving speed, but the adjustment of laser power causes a large change in the flexural strength. When the laser power was adjusted from 0.3 to $0.45 \mathrm{~W}$ and the laser scanning speed was also increased to $750 \mathrm{~mm} \cdot \mathrm{s}^{-1}$, the flexural strength of ceramics was improved from 622 to $978 \mathrm{MPa}$, and the density has been at a high level $(98.3 \%-$ 98.7\%). Fu et al. [84] further studied the changes in density and performance of ceramic parts obtained by different laser powers. Within a certain range, the combination between adjacent layers is linearly related to the laser power. The manifestation in performance is that as the power of the light source is gradually increased, the flexural strength of the layered surface also increases. However, high laser power generates a large amount of heat excessive to burn out the resin, leading to the suspension being unable to solidify. Additionally, the increased laser power undoubtedly widens the solidified area of the slurry, so the weight and size of parts gradually increase after printing. But the increase in weight is less than that in size, so the density of the printed green body decreases instead. Curiously, the density of ceramic parts after sintering is proportional to the laser power for the reason that the penetration width and depth also increase, thus shortening the distance between adjacent curing lines, as shown in Fig. 19. In addition to the laser power and scanning velocity that affect the dimensional accuracy and density of the part, it is reasonable to propose that different scanning paths may have different effects. Xing et al. [101] used SLA to make $\mathrm{ZrO}_{2}$ ceramic rods and investigated the influence of the scanning paths. Due to the different scanning paths, the obtained ceramics show anisotropy in both horizontal and vertical directions, and the surface roughness is also different. The density of all sintered materials can reach about $99.3 \%$. The resulting average flexural strength, hardness, and fracture toughness can reach up to $1336 \mathrm{MPa}, 14.52 \mathrm{GPa}$, and $6.62 \mathrm{MPa} \cdot \mathrm{m}^{1 / 2}$, respectively, which are consistent with conventional methods. The defect of the prepared zirconia structure was that the density is not uniform that is confirmed by SEM observation, as displayed in Figs. 20(a) and 20(b). In the high-density area, the particles are clustered, and the grain boundaries become strong. While, holes with randomly distributed elliptical features can be clearly observed in the low-density area, and there are unique floccules around the area. EDS spectra (Figs. 20(c) and 20(d)) showed that the content of $\mathrm{C}$ in $\mathrm{ZrO}_{2}$ particles is much lower than that in floccule, indicating that the floccule was likely to be the organic resin remaining after high-temperature heating. Printing direction also affects adhesion between layers. Osman et al. [102] ingeniously studied the printing accuracy and mechanical properties of $\mathrm{ZrO}_{2}$ implants by changing directions. Analysis of experimental data showed that the ceramic product has the maximum bending strength in the vertical printing direction. The SEM images revealed obvious cracks on the surface of the sample. The inhomogeneous shrinkage of the uneven layered structure may be caused during the high-temperature sintering process, which indicates that the adhesion between the layers is weaker than that between the layers in the printed layer, causing interlayer cracking and thus affecting the density of the sintered part [103]. Depositing a ceramic matrix inside the preform by infiltration can effectively increase the ceramic density and improve the porosity. Using this idea, Cheng et al. [9] combined SLA with chemical vapor infiltration to prepare $\mathrm{Si}_{3} \mathrm{~N}_{4}-\mathrm{Si}_{3} \mathrm{~N}_{4}$ composites. When no deposition method is applied, the porosity of the ceramic is $68.65 \%$, and the density is only $0.99 \mathrm{~g} / \mathrm{cm}^{3}$. However, after deposition for $12 \mathrm{~h}$, the prepared
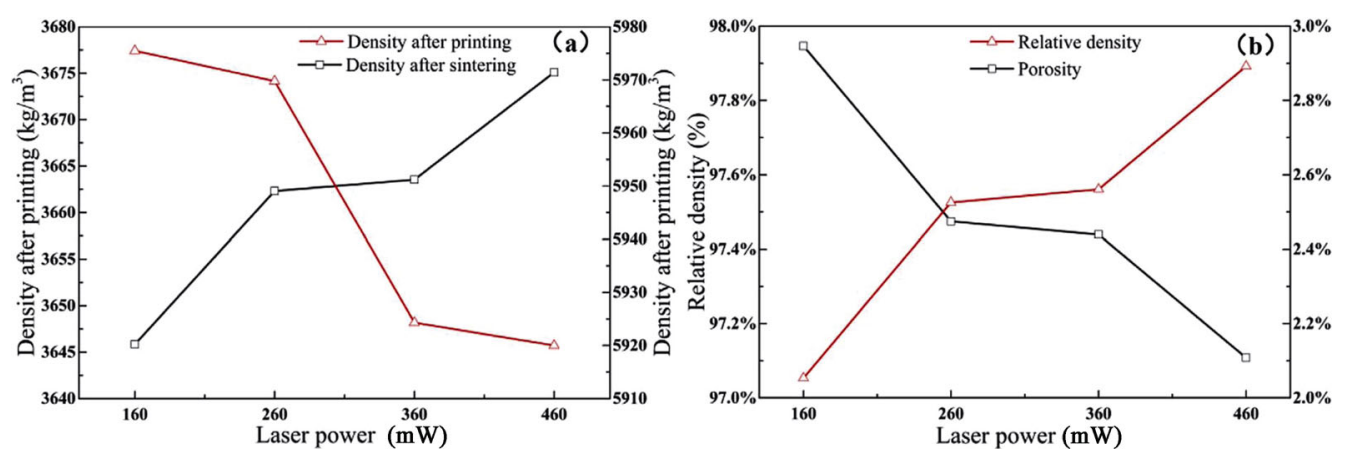

Fig. 19 (a) Changes in density of ceramic parts after printing and sintering, and (b) relative density and porosity of sintered parts as a function of laser power (reproduced with permission from Ref. [84], (C) Elsevier Ltd and Techna Group S.r.1. 2019). 


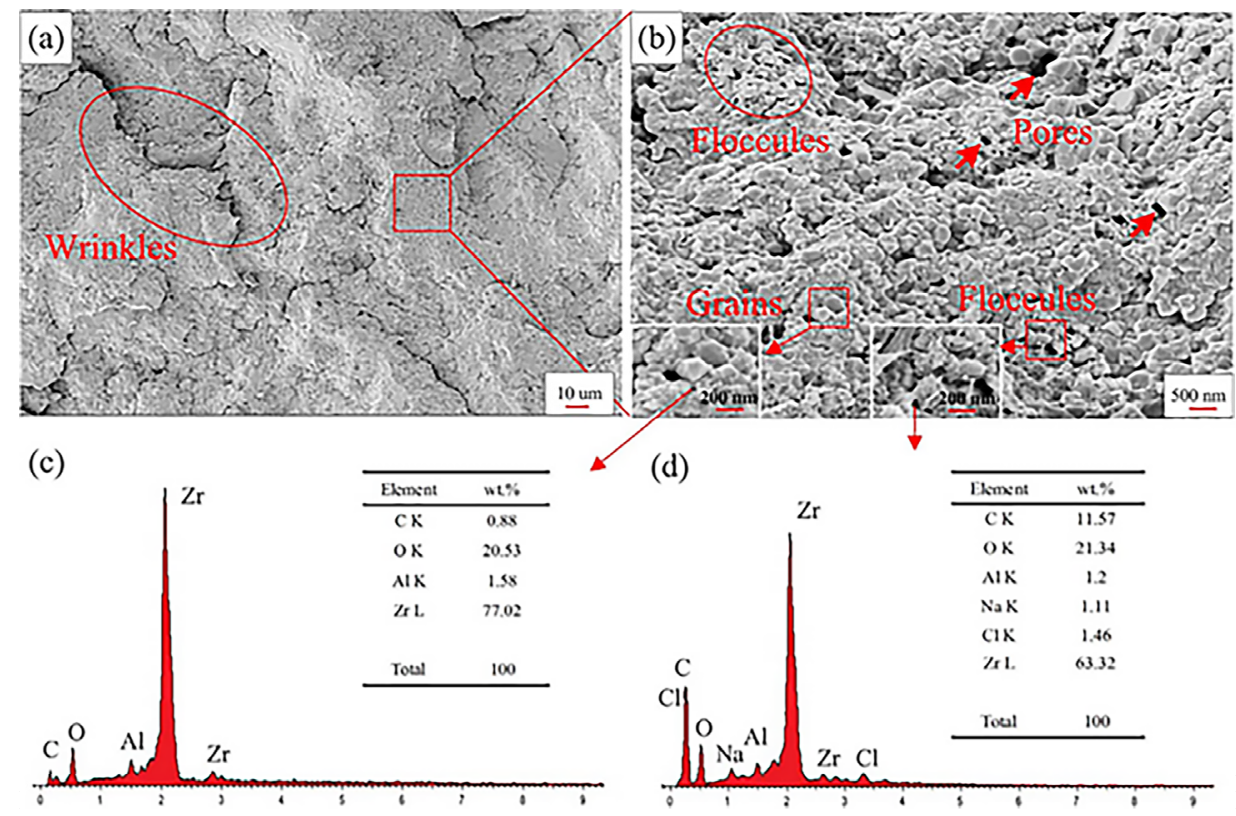

Fig. 20 SEM micrographs $(a, b)$ and (c, d) EDS spectra of fracture surface of zirconia ceramics (reproduced with permission from Ref. [101], (C) Elsevier Ltd and Techna Group S.r.1. 2017).

$\mathrm{Si}_{3} \mathrm{~N}_{4}-\mathrm{Si}_{3} \mathrm{~N}_{4}$ composite ceramics have a porosity of $26.07 \%$ and a density of $2.02 \mathrm{~g} / \mathrm{cm}^{3}$. Combined with previous research, it can be deduced that the printing process and post-processing of SLA treated samples should be further studied to achieve better density [104]. Many studies [10,105] have shown that some post-processing methods (such as post-curing or heating) can also be adopted to improve the density of ceramics made by SLA to further achieve the required mechanical properties. By controlling the thermal heating process of degreasing and sintering, Zhang et al. [106] obtained ceramic bodies sintered with excellent mechanical rigidity, whose relative density was > $99.0 \%$. This method can also be used to fabricate complex and dense ceramic products with precision as low as $0.065 \mathrm{~nm}$.

The molding principle of the digital light processing (DLP) technology derived from SLA is that ultraviolet light is directly irradiated to the mixture of photosensitive resin and ceramic powder to achieve the curing of the entire layer. After one layer is completed, the control system only needs to move the $Z$ axis and continue to use light to print the object layer by layer [107]. Different from the dot-line printing method of SLA, the DLP has rapid prototyping efficiency. Baumgartner et al. [108] developed a ceramic suspension with a solid content as high as $73 \mathrm{wt} \%$ for DLP. In studying the rheological behavior of the slurry, they found that the slurry filled with the large and round particle showed a lower viscosity than the base material while reducing the initial flow resistance, which is more conducive to the printing process. The prepared ceramic crown showed that the average dimensional error of the printed green body was $\pm 50 \mu \mathrm{m}$. After sintering and polishing, the density was $2.5 \mathrm{~g} / \mathrm{cm}^{3}$, achieving a density value higher than the theoretical density of $99.9 \%$. At the same time, the average flexural strength was up to $430 \mathrm{MPa}$ (the human dentin is $160 \mathrm{MPa}$ ), which sufficiently met the requirements of the accuracy and bending strength of dental restorations. Lian et al. [86] used DLP technique and a three-part auxiliary bracket to make typical molar crown bridges. The printed ceramic conforms to the preset shape, and the size error does not exceed $0.15 \mathrm{~mm}$. The relative density of the sintered ceramics is $99.3 \%$, and the three-point bending strength is $541 \pm 160 \mathrm{MPa}$, which is fully in line with dental applications. In addition to bioceramics, SLA also has unique advantages for piezoelectric ceramics. While the dielectric properties meet the actual requirements, the ceramic parts with complex shapes have injected new vitality into the further application of piezoelectric ceramics. The relationship between the density and performance of piezoelectric ceramics represented by $\mathrm{BaTiO}_{3}$, as shown in Table 2.

$8 \mathrm{~mol} \%$ Yttria-stabilized-zirconia (8YSZ), which is 
Table 2 A summary of the latest research on the preparation of $\mathrm{BaTiO}_{3}$ ceramic parts by SLA

\begin{tabular}{ccccc}
\hline $\begin{array}{c}\text { Density } \\
\left(\mathrm{g} / \mathrm{cm}^{3}\right)\end{array}$ & $\begin{array}{c}\text { Piezoelectric } \\
\text { coefficient } \\
(\mathrm{pC} / \mathrm{N})\end{array}$ & Authors & $\begin{array}{c}\text { Year of } \\
\text { publication }\end{array}$ & Ref. \\
\hline 5.96 & 60 & Zeng et al. & 2020 & {$[109]$} \\
5.70 & 87 & Song et al. & 2017 & {$[110]$} \\
5.69 & 163 & Wang et al. & 2020 & {$[111]$} \\
5.65 & 166 & Cheng et al. & 2019 & {$[112]$} \\
5.64 & 160 & Chen et al. & 2016 & {$[113]$} \\
\hline
\end{tabular}

currently one of the most commonly used materials of SOFC, has also been prepared by DLP technology. Ruiz-Morales et al. [114] used 8YSZ to prepare SOFC components with excellent morphology, but the electrical performance test was not satisfactory due to the porous microstructure. Generally speaking, electrolytes are not suitable for SOFC due to void formation, unless the porosity in the electrolyte layers is desirable. This is because the dense electrolyte can not only provide the necessary mechanical support but also promote high ionic conductivity [115]. 3D printing of dense electrolyte can simplify the manufacturing process, avoiding the manual assembly of multiple joints and seals from single cells to SOFC components, and the electrochemical performances of cells with the electrolyte by $3 \mathrm{D}$ printing are comparable to those by traditional method. Wei et al. [116] fabricated a $500 \mu \mathrm{m}$ flat $8 \mathrm{YSZ}$ electrolyte for SOFC by DLP using a mixed suspension containing $30 \%$ volume fraction of $8 \mathrm{YSZ}$ and photosensitive resin. The density of the sintered electrolyte at $1550{ }^{\circ} \mathrm{C}$ was $99.96 \%$. The SOFC with the structure of Ag-GDC|YSZ|Ag-
GDC has a peak power density of $176 \mathrm{~mW} \cdot \mathrm{cm}^{-2}$ at $850{ }^{\circ} \mathrm{C}$, which is 1.5 times that of traditional dry-pressed electrolytes. Subsequently, Xing et al. [117] prepared a plate-like 8YSZ electrolyte with a thickness of only $200 \mu \mathrm{m}$ through DLP technology. Furthermore, completely dense ceramics with a density of $97.5 \%$ was obtained at $1450{ }^{\circ} \mathrm{C}$. Corresponding to this, the total conductivity of the dense electrolyte is as high as $2.18 \times 10^{-2} \mathrm{~S} \cdot \mathrm{cm}^{-1}$, which is fully in line with practical applications. The maximum power density of $114.3 \mathrm{~mW} \cdot \mathrm{cm}^{-2}$ was tested in a self-supporting SOFC made of Ni-8YSZ cermet and LSM as anode and cathode. In addition, the flexibility of 3D printing technology provides feasibility for the design of the micro-scale of the electrolyte. Xing et al. [118] printed a wave-like 8YSZ electrolyte based on their previous work. Compared with the flat electrolyte of the same thickness, this specially designed structure increases the electrode-electrolyte contact area by $36 \%$, so the maximum power density of the prepared SOFC was increased to $151.2 \mathrm{~mW} \cdot \mathrm{cm}^{-2}$. It can be seen from Table 3 about the comparison of the electrochemical performance of the dense electrolyte SOFC prepared by DLP technology. It can be found that the current ceramic electrolyte for $3 \mathrm{D}$ printing SOFC still has some problems that need to be broken through, such as difficulty in preparing an electrolyte that is thin enough to be self-supporting and developing special structures to further increase the electrodeelectrolyte contact area $[119,120]$.

Since ceramic powder is generally hard to dissolve in the slurry, the prepared suspension will inevitably

Table 3 Comparison of self-supporting electrolyte SOFC fabricated by DLP

\begin{tabular}{|c|c|c|c|c|c|c|c|}
\hline Ref. & $\begin{array}{l}\text { Peak power density } \\
\left(\mathrm{mW} \cdot \mathrm{cm}^{-2}\right)\end{array}$ & $\begin{array}{l}\text { Total conductivity } \\
\quad\left(10^{-2} \mathrm{~S} \cdot \mathrm{cm}^{-1}\right)\end{array}$ & Thickness $(\mu \mathrm{m})$ & SOFC structure & Temp. $\left({ }^{\circ} \mathrm{C}\right)$ & OCV (V) & Shape \\
\hline \multirow{2}{*}{ [121] } & - & 3.0 & 250 & \multirow{2}{*}{ NiO-YSZ/8YSZ/LSM-YSZ } & 800 & \multirow{2}{*}{1.10} & \multirow{2}{*}{ Ripple } \\
\hline & 410 & - & - & & 900 & & \\
\hline \multirow[b]{2}{*}{ [118] } & 151.2 & \multirow[b]{2}{*}{2.1} & 200 & \multirow[b]{2}{*}{ NiO-8YSZ/8YSZ/LSM } & \multirow[b]{2}{*}{800} & \multirow[b]{2}{*}{1.05} & \multirow[b]{2}{*}{ Ripple } \\
\hline & 197.6 & & & & & & \\
\hline$[117]$ & 114.3 & 2.18 & 200 & NiO-8YSZ/8YSZ/LSM & 800 & 1.10 & Flat \\
\hline \multirow{4}{*}{ [122] } & 69 & - & \multirow{2}{*}{260} & \multirow{4}{*}{-Ni-YSZ/3YSZ/LSM-YSZ } & 800 & \multirow{4}{*}{1.14} & \multirow{2}{*}{ Honeycomb } \\
\hline & 115 & - & & & 900 & & \\
\hline & 60 & 1.1 & \multirow{2}{*}{340} & & 800 & & \multirow{2}{*}{ Flat } \\
\hline & 100 & 2.2 & & & 900 & & \\
\hline \multirow{2}{*}[116]{} & 116 & \multirow{2}{*}{ - } & \multirow{2}{*}{500} & \multirow{2}{*}{$\mathrm{Ag}-\mathrm{GDC} / 8 \mathrm{YSZ} / \mathrm{Ag}-\mathrm{GDC}$} & 800 & \multirow{2}{*}{1.04} & Flat \\
\hline & 176 & & & & 850 & & Flat \\
\hline
\end{tabular}


precipitate during long-term storage or printing, resulting in unevenness in the overall structure of the parts after drying and sintering. In addition, the functions of ceramics have become more diverse, which requires ceramics with complex compositions. However, the chemical stability of ceramics makes this requirement very difficult. The polymer-derived ceramic (PDC) technology that has emerged in recent years first synthesizes polymers that meet certain conditions through molecular design and chemical synthesis, namely preceramic polymers (PP). Then, the target ceramic can be prepared by cracking the solidified ceramic precursor at high temperature, which is defined as polymer-derived ceramic (PDC) [123]. This special precursor is considered to be expected to replace traditional light-curing ceramic slurry, because PDC can be uniformly dispersed in various solutions without worrying about the unevenness and light absorption. Eckel et al. [5] developed a new type of photocurable siloxane resin system. The resulting resin was used in SLA to prepare larger micro-lattices and honeycomb structures for mechanical performance testing. The molded PDC was obtained after pyrolysis at $1000{ }^{\circ} \mathrm{C}$ in an inert atmosphere. Although $42 \%$ of mass loss inevitably occurred during the pyrolysis process, SEM and TEM showed that the SiOC ceramic with a linear shrinkage of $30 \%$ was completely dense without any pores and cracks. The honeycomb structure ceramic with a density of $0.8 \mathrm{~g} / \mathrm{cm}^{3}$ has been measured to obtain a compressive strength of $163 \mathrm{MPa}$. What is gratifying is that compared with the mechanical properties of ceramic foams of similar density, the compressive strength of porous $\mathrm{SiOC}$ fabricated by SLA is about 10 times that of similar ceramic materials, which can be used in the micro-electromechanical system and the jet engine.

Although PDC technology has unique advantages when applying to $3 \mathrm{D}$ printing, a large amount of gas is released during pyrolysis, thereby creating pores in the printed structure. By introducing fillers into the suspension, the volume shrinkage and the number of cracks can be reduced to further improve the dimensional stability and mechanical properties [124]. The function of the filler is mainly to absorb gas by-products to increase the yield of ceramics and to produce volume expansion to compensate for shrinkage. Some special fillers combined with the reactivity of PP can provide surprising compositions and functions. Li et al. [125] studied the influence of the powder properties of $\mathrm{Si}_{3} \mathrm{~N}_{4}$ on the rheology and curing ability of the photocurable slurry. The viscosity of the silicon nitride slurry after introducing part of the coarse silicon powder particles decreased significantly, further confirming the benefit of the bimodal distribution of the powder particle size on the rheological properties of the photocured slurry. Compared with oxide powder, in addition to the large refractive index, the large absorbance of nitride powder is also an important reason for the difficulty of photocuring. This is because the absorbance affects the light energy acting on the photosensitive resin and makes the curing performance worse. Alongside this, the outstanding contribution of the research is to compare two photocurable monomers and found that the high molecular weight monomer may be easier to obtain a higher curing depth, which is beneficial to the molding of non-oxide ceramics. The use of conventional slurry to form non-oxide ceramics by light curing seems to have reached a certain impasse. Researchers have taken another approach to manufacture non-oxide ceramic parts through the PDC route and achieved excellent results. Gyak et al. [126] developed a new type of ceramic precursor for 3D printing of fully dense silicon carbonitride ceramic bodies, and manufactured SiCN ceramics of various structures with only $20 \%$ low weight loss. The printed body was prepared from a resin slurry containing modified polyvinylsilazane as a ceramic composite polymer and silica particles as a filler. It can be converted into SiCN ceramics after complete pyrolysis in argon at $1000{ }^{\circ} \mathrm{C}$ for $3 \mathrm{~h}$. The density of sintered ceramic was $2.28 \mathrm{~g} / \mathrm{cm}^{3}$, and the isotropic linear shrinkage was only $20 \%$. By comparing the mechanical properties of the ceramic without adding silica filler and after adding filler, the results showed that the modulus and hardness of SiCN ceramics with silicon fillers have been significantly improved: the modulus is increased from 68 to $78 \mathrm{GPa}$, and the Vickers hardness is increased from 8 to $10 \mathrm{GPa}$. In addition, Schmidt et al. [127] introduced alumina powder as an active filler into a commercially available photosensitive polysiloxane to create dense and crackfree porous mullite structures through DLP. The measured density of the structure was $98.1 \%$ of the theoretical density. Polysiloxane acts as a source of $\mathrm{Si}$, which can react with alumina during pyrolysis to form mullite. From the SEM image, the structure was composed of rhombic-octahedral units with eight equilateral triangles and eighteen squares, as shown in Fig. 21. Obvious delamination has not been observed 


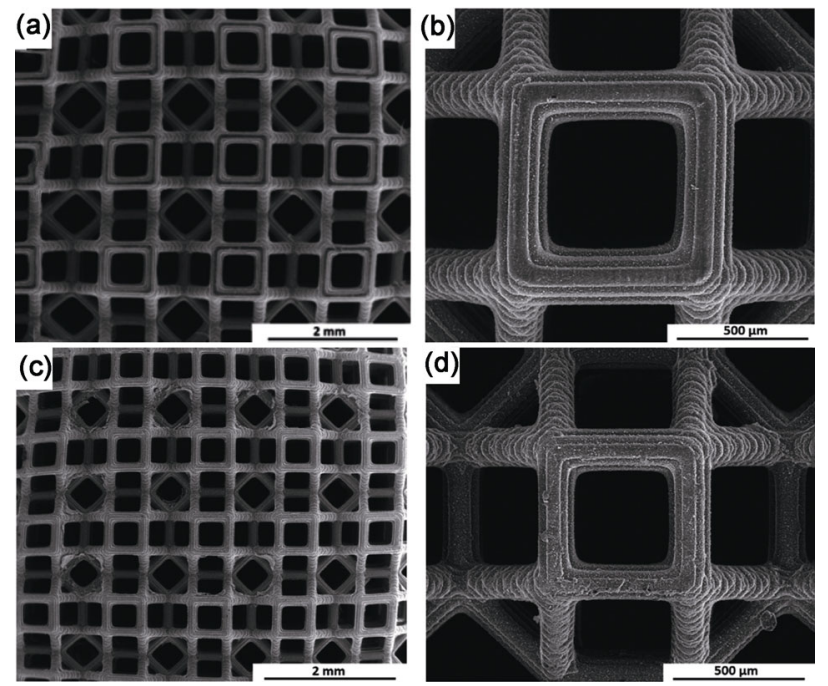

Fig. 21 SEM of the structure printed with the phase optimized polysiloxane/micron alumina mixture before (a, b) and after (c, d) sintering at $1300{ }^{\circ} \mathrm{C}$ (reproduced with permission from Ref. [127], (C) Elsevier Ltd. 2018).

in the sintered ceramic, and the isotropic shrinkage rate of the ceramic is $36 \%$, thus perfectly maintaining the original shape. The sample with total porosity of $90 \mathrm{vol} \%$ showed a flexural strength of $1.8 \pm 0.3 \mathrm{MPa}$ through preliminary mechanical tests. Therefore, it is undoubtedly a feasible idea to combine fillers with pre-ceramic polymers and then prepare dense ceramics with excellent properties through $3 \mathrm{D}$ printing.

\section{Direct ink writing}

In recent years, there has been a flourishing interest in utilizing direct ink writing (DIW) to manufacture ceramics. As the name implies, ceramic DIW technology mixes the ceramic powder with the binder, dispersant, and other additives into a shear-thinning ink material (regardless of droplets or paste) extruded through a certain diameter printing nozzle [128]. Therefore, it is generally regarded as a kind of extrusion-free-forming (EFF) technology [129]. The difference between DIW and EFF is that the DIW technology uses a ceramic slurry with a relatively low solid content and viscosity compared to the EFF process. The pre-designed shape of a ceramic body is obtained by stacking ink layers layer by layer, and then the required ceramics are prepared by high-temperature degreasing and sintering. The schematic illustration of DIW is proposed in Fig. 22 [130]. It is easy to find that DIW technology has significant advantages not available in other $3 \mathrm{D}$ printing technologies: it can be undergone without the need for any heating or ultraviolet or laser radiation [131]. Compared with SLA technology, this advantage makes the DIW manufacturing process cheaper and more precise control of micro and macro structures $[132,133]$. As mentioned before, the decisive factor to obtain 3D printed ceramics with high density is to maximize the ceramic solid content in the printing paste [134]. On the premise of ensuring printability, it can be seen from Fig. 23 that the same applies to DIW technology [135]. Selecting the most appropriate rheological properties for the ink is, therefore, essential. Recently, Eqtesadi et al. [136] adopted the combination of DIW and pressureless spark plasma sintering to

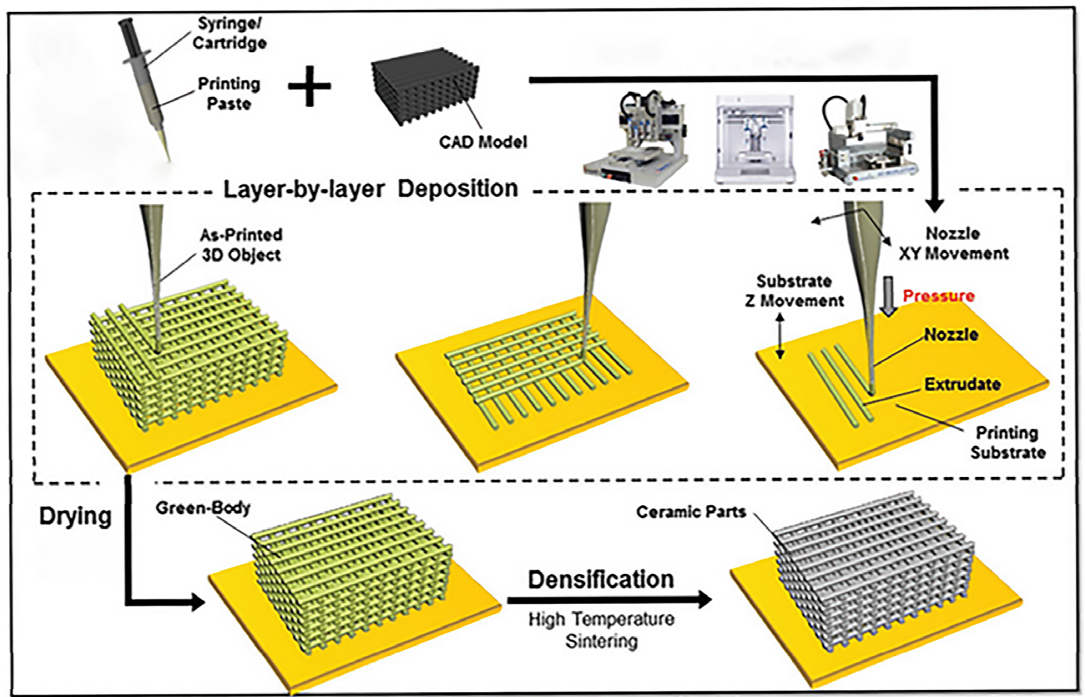

Fig. 22 Schematic diagram of the DIW process (reproduced with permission from Ref. [130], (C) WILEY-VCH Verlag GmbH \& Co. KGaA, Weinheim 2018). 


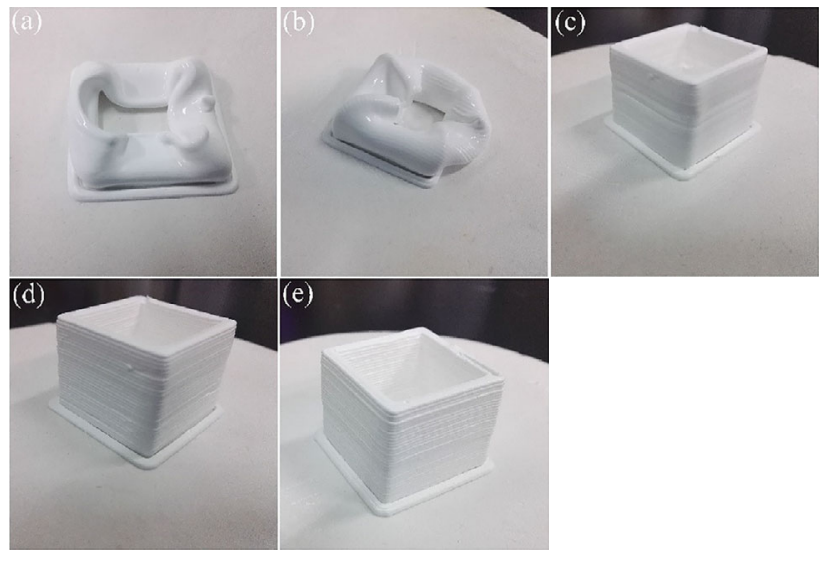

Fig. 23 Ceramic ink with different $\mathrm{TiO}_{2}$ content for DIW: (a) $56 \mathrm{wt} \%$, (b) $60 \mathrm{wt} \%$, (c) $64 \mathrm{wt} \%$, (d) $68 \mathrm{wt} \%$, (e) $72 \mathrm{wt} \%$ (reproduced with permission from Ref. [135], (C) Elsevier B.V. 2018).

realize the ultra-fast and highly efficient densification process of $\mathrm{B}_{4} \mathrm{C}$ ceramic parts with complex shapes. The density of ceramics reaches $95 \% \pm 3 \%$ at $2100{ }^{\circ} \mathrm{C}$ after sintering, a near-fully dense state, as shown in Fig. 24. The hardness of sintered $\mathrm{B}_{4} \mathrm{C}$ ceramics is $27 \mathrm{GPa}$ while the compressive strength is $1800 \mathrm{MPa}$. Although DIW is very suitable for the preparation of customized structures with periodic characteristics, the organic binder used in this process will still severely alter the compactness of ceramics and the sintering strength $[137,138]$. In this review, to achieve a better understanding of factors influencing the production of high-density ceramics using DIW, we will focus on the extrusion method, in which the slurry with relatively high solid content and viscosity is used at room temperature.

DIW does not require the participation of ultraviolet or laser to make ceramics according to the molding principle of DIW. The semi-liquid ink is extruded directly from the nozzle of a printing equipment layer by layer and cured into the desired shape because of

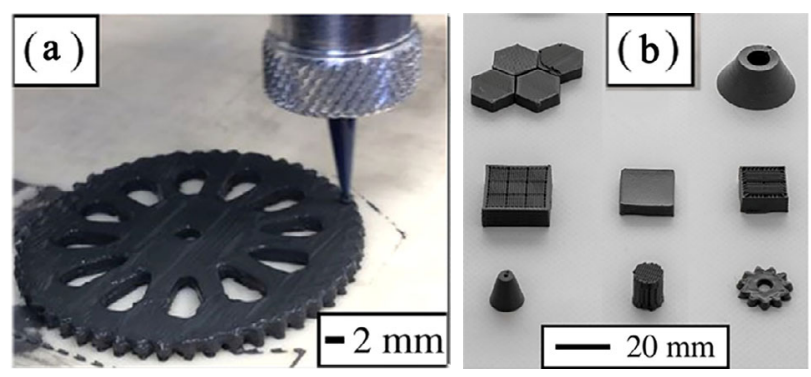

Fig. 24 (a) Geometrically-complex gear being printed, (b) $\mathrm{B}_{4} \mathrm{C}$ green parts made with DIW (reproduced with permission from Ref. [136], (C) Acta Materialia Inc. 2017). the viscoelasticity and high ceramic volume fraction. The green body obtained is subjected to debinding and high-temperature sintering to acquire a ceramic material component. Therefore, the nature of the ink is very important and the ink must meet the requirements for rheological performance during printing [139]. The inks in a DIW process need to first ensure that once deposited on the substrate, they can be cured and maintained in shape. Second, when the shear stress is greater than a certain threshold value, the ink should exhibit a shear-thinning property, ensuring that the ceramic ink smoothly passes through the pipes and nozzles without blocking [140]. Rueschhoff et al. [141] have directly built net-like dense ceramics at normal temperature with the help of DIW. The flow curve (Fig. 25) showed that solid content has nearly no effect on the yield-pseudo-plastic behavior of the suspension. As the solid content increases, the viscosity and yield stress of the suspension also increase. Suspensions with too high solid content are very difficult to squeeze out due to its high viscosity and may clog the nozzle. Oppositely, if ink with a too low solid content was designed, it is very difficult to support subsequently deposited layers during printing [142]. It is, therefore, necessary to determine the appropriate solid content.

It was further proposed in another study [135] that the shape could be retained after extrusion when the elastic modulus of the ink falls within a proper range, which is very beneficial for DIW. The elastic modulus of a suspension can be evaluated by Eq. (3):

$$
y=k\left(\frac{\phi}{\phi_{\text {gel }}}-1\right)^{x}
$$

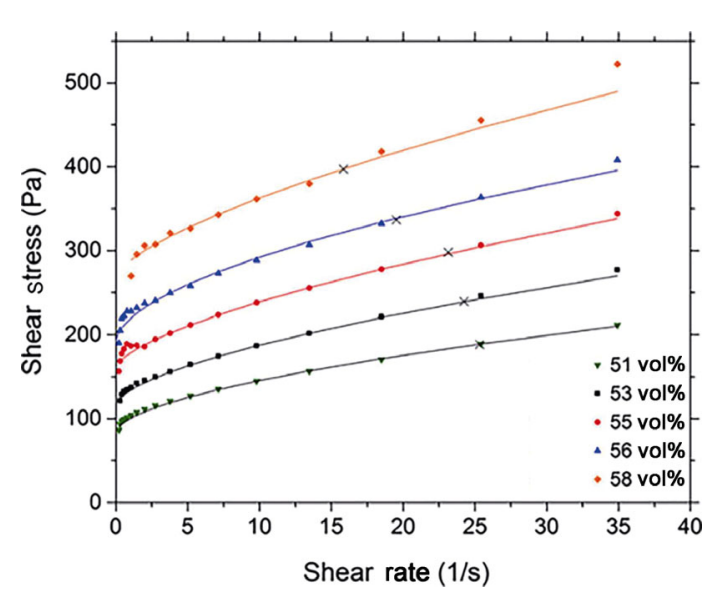

Fig. 25 Flow curve for alumina inks varying with solid content (reproduced with permission from Ref. [141], (C) Elsevier Ltd. 2016). 
where $y$ is the elastic constant, $k$ is a constant, $\phi_{\text {gel }}$ is the gel point, $\phi$ is the volume fraction of colloidal gels, and $x$ is the scaling exponent. In addition, the rheology of printing inks during DIW can be adjusted through the interaction of different hydrogen bonds between polar and non-polar solvent particles. Jin et al. [143] used DIW technology to manufacture high-strength $\mathrm{Si}_{2} \mathrm{~N}_{2} \mathrm{O}$ ceramic parts by mixing different volume ratios of high-boiling solvents and $\left(\mathrm{NH}_{4}\right) \mathrm{H}_{2} \mathrm{PO}_{4}$ aqueous solutions into the ink. The prepared flocculent ink liquefies under high shear strain and then returns to its original state after being converted to a low shear environment, which could signify that the ink is easily released to deposit and immediately reconstruct the micro-network to maintain its structure. After introducing $\left(\mathrm{NH}_{4}\right) \mathrm{H}_{2} \mathrm{PO}_{4}$ and then applying hightemperature heat, the ceramic sample exhibited the compressive strength of $3.33 \mathrm{MPa}$ at a maximum density of $1.14 \mathrm{~g} / \mathrm{cm}^{3}$. The increase in porosity will breed a large number of unsaturated bonds, which will undoubtedly lead to an increase in dielectric loss and a decrease in dielectric constant. Unlike other 3D printing technologies introduced, the ink used in DIW technology requires the printed filaments to be quickly solidified to have sufficient strength to support the subsequent layers, otherwise the entire printing parts will collapse. This requires that in addition to uniformity and high solid content, the rapid curing ability of the slurry is very important, especially for slope printing without support. Yang et al. [144] applied the heat-induced curing properties of carrageenan to DIW for $3 \mathrm{D}$ printing of complex alumina parts. The ink composed of $0.2 \%-0.6 \%$ by weight of carrageenan, $0.11 \%$ by weight of ammonium citrate as a dispersant, and $56 \%$ by volume of alumina powder is sufficient to print complex parts with a slope of more than $60^{\circ}$ without support, as shown in Fig. 26. After heating the paste containing an appropriate amount of carrageenan to $55{ }^{\circ} \mathrm{C}$, the viscosity of the carrageenan increases greatly due to the heat expansion and absorption of a large amount of water. Coupled with the high solid content, fast curing can be achieved when extruding filaments, as shown in Fig. 27. However, too high concentration of carrageenan will cause a part of the paste to solidify first at high temperature, while other pastes are still at a lower temperature, resulting in discontinuities in the paste during the printing process. Thanks to the high solid content ink and the optimization of printing parameters, the sintered alumina ceramics

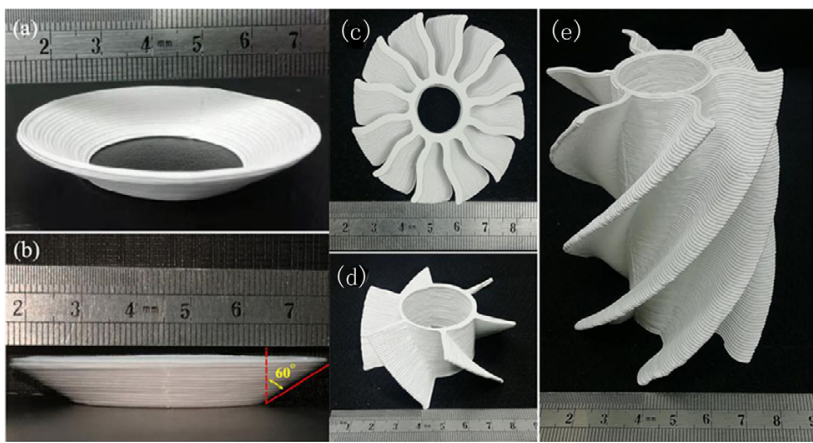

Fig. $26 \mathrm{Al}_{2} \mathrm{O}_{3}$ green body with $60^{\circ}$ inclined-plane printed $(\mathrm{a}, \mathrm{b})$ and with impeller structure $(\mathrm{c}-\mathrm{e})$ (reproduced with permission from Ref. [144], (C) The Author(s) 2020).

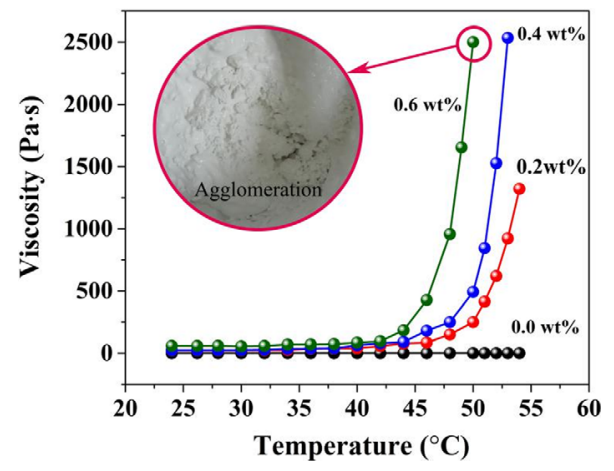

Fig. 27 Viscosity change of alumina ink containing different concentrations of carrageenan after heating (reproduced with permission from Ref. [144], (C) The Author(s) 2020).

with a relative density of $97.6 \%$ have a bending strength of $250.86 \mathrm{MPa}$ and a Vickers hardness of $18.91 \mathrm{GPa}$.

Although a lot of work has been carrying out, DIW still has some problems to be resolved. Compared to the aforementioned SLA and DLP processes, the resolution of DIW molding based on extrusion has always been a disturbing problem due to the step effect [145]. The printing parameters such as layer height, printing speed, and filling have a vital influence on printing resolution. Buj-Corral et al. [146] studied the influence of printing parameters on the printing resolution of porous zirconia parts during the DIW process. Experimental results showed that the combination of low filling and high printing speed is conducive to achieving the lowest surface roughness. This is because low filling means that it is not necessary to deposit materials on each layer, and high printing speed can shorten the printing time and improve production efficiency. In addition, due to the discharge of additives such as binders and dispersants 
during the drying and sintering process, the size of the molded parts will change. This can be achieved by studying the relationship between the volume shrinkage of the parts and the filling density. In this way, the geometric shape of the part was scaled up in the three-dimensional design process, so that the parts of the required size can be obtained after sintering. Rosental et al. [147] provided a new idea to minimize the shrinkage of $\mathrm{BaTiO}_{3}$ ceramics prepared by DIW after sintering. The biggest feature of the new ink formula they used is that the particles and the adhesive are the same material. Using barium acetate and titanium isopropoxide as precursors, water and acetic acid as solvents, a $\mathrm{BaTiO}_{3}$ sol adhesive was obtained through a sol-gel process. Due to the extremely low content of organic additives, the sintering shrinkage was also low. The $\mathrm{BaTiO}_{3}$ ceramic sintered at $1500{ }^{\circ} \mathrm{C}$ reached $97.8 \%$ of the theoretical density. The increase in density causes an increase in dielectric properties, and the dielectric permittivity measured at $10 \mathrm{kHz}$ is 533. On top of that, the minimum molding diameter of ceramic inks configured can only be as low as $10 \mu \mathrm{m}$ due to the limitation of the size of ceramic particles, which greatly affects the preparation of micro ceramic devices. Therefore, it is still necessary to continue to explore practical and feasible ink formulations, such as the use of the reverse microemulsion method to prepare highly stable and well-dispersed ceramic inks [148].

\section{Conclusions}

This review details the four 3D printing technologies used in ceramic manufacturing and discusses the possibility of preparing high-density ceramics through each process and cutting-edge strategy, supplemented by numerous examples. It should be pointed out that the technologies mentioned in this review can all be used to manufacture high-density ceramic parts by optimizing powder properties, printing parameters, and post-processing methods within their limits, but each technology still faces great challenges and infinite possibilities for improvement.

The powder characteristics and the variable energy acting on the powder determine the structure and density of the final ceramic parts produced by the powder bed method (including SLS and SLM). The particle size distribution of the spherical powder is very important for the powder bed processing technology. In particular, it is necessary to consider powder fluidity and reduce agglomeration. The laser energy output strategies need to continue to be studied to better sinter or melt ceramic powder. The thermal stress inevitably caused by the thermal gradient after printing the product is still the main source of cracks and deformation. In addition, the rough surface of the processed parts and the large shrinkage during the sintering process severely limit its application range. For SLA technology, it is difficult to prepare non-oxide ceramics with better performance in the traditional light-curing ceramic slurry because the light absorption and light transmission properties of the ceramic powder cannot be well adapted to the laser. Although the emergence of ceramic precursor polymers and the introduction of fillers have greatly improved the difficulty of forming ceramics, the types of polymers and the large shrinkage rate after sintering still need to be improved. DIW is easy to operate and suitable for mass production. However, the solid content of ceramics currently used for DIW is still low, which makes it difficult to form dense ceramic bodies with satisfactory mechanical properties. The rapid curing ability of the extruded slurry still needs the research of new curing technology or unique ink formulation. In addition, after sintering, it is often difficult to control the molding size due to the large shrinkage. Therefore, ceramic ink formulations with high solid content and excellent rheological properties still need to be further developed.

From this overall analysis, SLA, whose dimensional accuracy and surface quality are significantly better than other technologies in the current research, has its unique advantages in the application of preparing high-density ceramic parts. The future prospect of densified ceramics with complex structures is to minimize the amount of additives or even abandon the use of binders for direct ceramic 3D printing. In addition, ceramic $3 \mathrm{D}$ printing technology should try to achieve high size reproduction and surface quality, but the most important thing is to maximize the freedom of geometric design, which is incomparable by traditional manufacturing technologies.

\section{Acknowledgements}

The authors acknowledge the financial support by the National Natural Science Foundation of China (52073212, 
51772205, and 51772208) and General Program of Municipal Natural Science Foundation of Tianjin (17JCYBJC17000, 17JCYBJC22700).

\section{References}

[1] Shao HF, Yang XY, He Y, et al. Bioactive glass-reinforced bioceramic ink writing scaffolds: Sintering, microstructure and mechanical behavior. Biofabrication 2015, 7: 035010.

[2] Wang G, Krstic VD. Rapid prototyping of ceramic components-review. Candian Ceramics 1998, 67: 52-58.

[3] Xu J, Ding LY, Love PED. Digital reproduction of historical building ornamental components: From 3D scanning to 3D printing. Autom Constr 2017, 76: 85-96.

[4] Babilotte J, Guduric V, Le Nihouannen D, et al. 3D printed polymer-mineral composite biomaterials for bone tissue engineering: Fabrication and characterization. J Biomed Mater Res B Appl Biomater 2019, 107: 2579-2595.

[5] Eckel ZC, Zhou CY, Martin JH, et al. Additive manufacturing of polymer-derived ceramics. Science 2016, 351: $58-62$.

[6] Ngo TD, Kashani A, Imbalzano G, et al. Additive manufacturing (3D printing): A review of materials, methods, applications and challenges. Compos Part B: Eng 2018, 143: 172-196.

[7] Wu P, Wang J, Wang XY. A critical review of the use of 3 -D printing in the construction industry. Autom Constr 2016, 68: 21-31.

[8] Zhang XY, Huo WL, Liu JJ, et al. 3D printing boehmite gel foams into lightweight porous ceramics with hierarchical pore structure. J Eur Ceram Soc 2020, 40: 930-934.

[9] Cheng ZL, Ye F, Liu YS, et al. Mechanical and dielectric properties of porous and wave-transparent $\mathrm{Si}_{3} \mathrm{~N}_{4}-\mathrm{Si}_{3} \mathrm{~N}_{4}$ composite ceramics fabricated by $3 \mathrm{D}$ printing combined with chemical vapor infiltration. $J A d v$ Ceram 2019, 8: 399-407.

[10] Li H, Liu YS, Liu YS, et al. Thermal treatment of $\gamma-\mathrm{Al}_{2} \mathrm{O}_{3}$ for the preparation of stereolithography 3D printing ceramic slurries. Front Mater 2019, 6: 295.

[11] Jiamin W, Annan C, Mengyue L, et al. Preparation of ceramic materials used for selective laser sintering and related forming methods. Materials China 2017, 36: 575-582.

[12] Zhang L, Feih S, Daynes S, et al. Pseudo-ductile fracture of 3D printed alumina triply periodic minimal surface structures. J Eur Ceram Soc 2020, 40: 408-416.

[13] Liu XY, Zou B, Xing HY, et al. The preparation of $\mathrm{ZrO}_{2}-\mathrm{Al}_{2} \mathrm{O}_{3}$ composite ceramic by SLA-3D printing and sintering processing. Ceram Int 2020, 46: 937-944.

[14] Zekoll S, Marriner-Edwards C, Hekselman AKO, et al. Hybrid electrolytes with 3D bicontinuous ordered ceramic and polymer microchannels for all-solid-state batteries. Energy Environ Sci 2018, 11: 185-201.
[15] Qin W, Zijun H, Chencheng S, et al Influencing factors and stability control of the mechanical properties of ceramic insulation tiles. Aerospace Material Technology 2010, 40: 77-79.

[16] Bourell DL, Marcus HL, Barlow JW, et al. Multiple material systems for selective beam sintering. US Patent 4,944,817, 1990.

[17] Mazzoli A. Selective laser sintering in biomedical engineering. Med Biol Eng Comput 2013, 51: 245-256.

[18] Bourell D, Wohlert M, Harlan N, et al. Powder densification maps in selective laser sintering. $A d v$ Eng Mater 2002, 4: 663-669.

[19] Chen AN, Wu JM, Liu K, et al. High-performance ceramic parts with complex shape prepared by selective laser sintering: A review. Adv Appl Ceram 2018, 117: 100-117.

[20] Niu FY, Wu DJ, Ma GY, et al. Rapid fabrication of eutectic ceramic structures by laser engineered net shaping. Procedia CIRP 2016, 42: 91-95.

[21] Shahzad K, Deckers J, Boury S, et al. Preparation and indirect selective laser sintering of alumina/PA microspheres. Ceram Int 2012, 38: 1241-1247.

[22] Fu SY, Zhu M, Zhu YF. Organosilicon polymer-derived ceramics: An overview. J Adv Ceram 2019, 8: 457-478.

[23] Tang P. The manufacturing process and properties of porous cordierite ceramics by additive manufacturing. Thesis. Wuhan (China): Huazhong University of Science and Technology, 2016.

[24] Bertrand P, Bayle F, Combe C, et al. Ceramic components manufacturing by selective laser sintering. Appl Surf Sci 2007, 254: 989-992.

[25] Mussatto A, Groarke R, A-Hameed A, et al. Evaluation via powder metallurgy of nano-reinforced iron powders developed for selective laser melting applications. Mater Des 2019, 182: 108046.

[26] Krantz M, Zhang H, Zhu J. Characterization of powder flow: Static and dynamic testing. Powder Technol 2009, 194: 239-245.

[27] Muñiz-Lerma J, Nommeots-Nomm A, Waters K, et al. A comprehensive approach to powder feedstock characterization for powder bed fusion additive manufacturing: A case study on $\mathrm{AlSi}_{7} \mathrm{Mg}$. Materials 2018, 11: 2386.

[28] Cordova L, Campos M, Tinga T. Revealing the effects of powder reuse for selective laser melting by powder characterization. JOM 2019, 71: 1062-1072.

[29] Sofia D, Chirone R, Lettieri P, et al. Selective laser sintering of ceramic powders with bimodal particle size distribution. Chem Eng Res Des 2018, 136: 536-547.

[30] Pfeiffer S, Florio K, Makowska M, et al. Iron oxide doped spray dried aluminum oxide granules for selective laser sintering and melting of ceramic parts. Adv Eng Mater 2019, 21: 1801351 .

[31] Zou Y, Li CH, Liu JA, et al. Towards fabrication of high-performance $\mathrm{Al}_{2} \mathrm{O}_{3}$ ceramics by indirect selective laser sintering based on particle packing optimization. Ceram Int 2019, 45: 12654-12662. 
[32] Hao L, Savalani MM, Zhang Y, et al. Effects of material morphology and processing conditions on the characteristics of hydroxyapatite and high-density polyethylene biocomposites by selective laser sintering. P I Mech Eng L: J Mat 2006, 220: 125-137.

[33] Kruth JP, Mercelis P, van Vaerenbergh J, et al. Binding mechanisms in selective laser sintering and selective laser melting. Rapid Prototyping J 2005, 11: 26-36.

[34] Wang JC, Dommati H, Hsieh SJ. Review of additive manufacturing methods for high-performance ceramic materials. Int J Adv Manuf Technol 2019, 103: 2627-2647.

[35] Feng P, Deng YW, Duan SL, et al. Liquid phase sintered ceramic bone scaffolds by combined laser and furnace. Int J Mol Sci 2014, 15: 14574-14590.

[36] Yang S. Fundamentals of Petrophysics. Beijing: Petroleum Industry Press, 2011.

[37] Koos E. Capillary suspensions: Particle networks formed through the capillary force. Curr Opin Colloid Interface Sci 2014, 19: 575-584.

[38] Zhou Y, Hirao K, Yamauchi Y, et al. Effects of heating rate and particle size on pulse electric current sintering of alumina. Scripta Mater 2003, 48: 1631-1636.

[39] Shuai CJ, Gao CD, Nie Y, et al. Fabrication optimization of nanohydroxyapatite artificial bone scaffolds. Nano 2012, 7: 1250015.

[40] Ho HCH, Gibson I, Cheung WL. Effects of energy density on morphology and properties of selective laser sintered polycarbonate. J Mater Process Technol 1999, 89-90: 204-210.

[41] Fu WH, Liu K, Liu J, et al. SiC components via SLS combined with reaction sintering. China Mechanical Engineering 2018, 29: 2111-2118.

[42] Liu ZH, Nolte JJ, Packard JI, et al. Selective laser sintering of high-density alumina ceramic parts. In: Proceedings of the 35th International MATADOR Conference, 2007: 351-354.

[43] Xia S. Fabricating silicon carbide parts by selective laser sintering/cold isostatic pressing and post process. Master Thesis. Wuhan (China): Huazhong University of Science \& Technology, 2016.

[44] Liu K, Shi YS, Li CH, et al. Indirect selective laser sintering of epoxy resin- $\mathrm{Al}_{2} \mathrm{O}_{3}$ ceramic powders combined with cold isostatic pressing. Ceram Int 2014, 40: 70997106.

[45] Shirazi SFS, Gharehkhani S, Mehrali M, et al. A review on powder-based additive manufacturing for tissue engineering: Selective laser sintering and inkjet 3D printing. Sci Technol Adv Mater 2015, 16: 033502.

[46] Fayed EM, Elmesalamy AS, Sobih M, et al. Characterization of direct selective laser sintering of alumina. Int $J$ Adv Manuf Technol 2018, 94: 2333-2341.

[47] Tang HH, Chiu ML, Yen HC. Slurry-based selective laser sintering of polymer-coated ceramic powders to fabricate high strength alumina parts. J Eur Ceram Soc 2011, 31: $1383-1388$.
[48] Yang Y, Ragnvaldsen O, Bai Y, et al. 3D non-isothermal phase-field simulation of microstructure evolution during selective laser sintering. npj Comput Mater 2019, 5, Article No. 81.

[49] Liu K, Sun HJ, Tan YL, et al. Additive manufacturing of traditional ceramic powder via selective laser sintering with cold isostatic pressing. Int J Adv Manuf Technol 2017, 90: 945-952.

[50] Liu J, Zhang B, Yan CZ, et al. The effect of processing parameters on characteristics of selective laser sintering dental glass-ceramic powder. Rapid Prototyping J 2010, 16: $138-145$.

[51] Liu K, Shi YS, Li CH, et al. Indirect selective laser sintering of epoxy resin- $\mathrm{Al}_{2} \mathrm{O}_{3}$ ceramic powders combined with cold isostatic pressing. Ceram Int 2014, 40: 7099 7106.

[52] Deckers JP, Shahzad K, Cardon L, et al. Shaping ceramics through indirect selective laser sintering. Rapid Prototyping J 2016, 22: 544-558.

[53] Jin LZ, Zhang K, Xu TT, et al. The fabrication and mechanical properties of $\mathrm{SiC} / \mathrm{SiC}$ composites prepared by SLS combined with PIP. Ceram Int 2018, 44: 20992 20999.

[54] Haijun S, Kaichen W, Wei G, et al. New development of laser rapid for (min)g and its application in high performance materials processing. The Chinese Journal of Nonferrous Metals 2013, 23: 1567-1574.

[55] Juste E, Petit F, Lardot V, et al. Shaping of ceramic parts by selective laser melting of powder bed. $J$ Mater Res 2014, 29: 2086-2094.

[56] Sing SL, Yeong WY, Wiria FE, et al. Direct selective laser sintering and melting of ceramics: A review. Rapid Prototyping J 2017, 23: 611-623.

[57] Stopyra W, Kurzac J, Gruber K, et al. Influence of laser power on the penetration depth and geometry of scanning tracks in selective laser melting. In: Proceedings of the SPIE 10159, Laser Technology 2016: Progress and Applications of Lasers, 2016: 101590R.

[58] Yang ZN, Jiang F, Wang XB, et al. Effect of electropulsing treatment on microstructure and mechanical properties of a deformed ZrTiAlV alloy. Materials 2019, 12: 3560.

[59] Yang ZT, Gao F, Du HL, et al. Grain size engineered lead-free ceramics with both large energy storage density and ultrahigh mechanical properties. Nano Energy 2019, 58: $768-777$.

[60] Wang ZG, Ouyang JH, Ma YH, et al. Grain size dependence, mechanical properties and surface nanoeutectic modification of $\mathrm{Al}_{2} \mathrm{O}_{3}-\mathrm{ZrO}_{2}$ ceramic. Ceram Int 2019, 45: 14297-14304.

[61] Liu Q, Danlos Y, Song B, et al. Effect of high-temperature preheating on the selective laser melting of yttriastabilized zirconia ceramic. J Mater Process Technol 2015, 222: 61-74.

[62] Frazier WE. Metal additive manufacturing: A review. $J$ Mater Eng Perform 2014, 23: 1917-1928. 
[63] El-Desouky A, Carter M, Mahmoudi M, et al. Influences of energy density on microstructure and consolidation of selective laser melted bismuth telluride thermoelectric powder. J Manuf Process 2017, 25: 411-417.

[64] Fateri M, Gebhardt A. Process parameters development of selective laser melting of lunar regolith for on-site manufacturing applications. Int $J$ Appl Ceram Technol 2015, 12: 46-52.

[65] Zhang K, Liu TT, Liao WH, et al. Experiment on selective laser melting forming of $\mathrm{Al}_{2} \mathrm{O}_{3}$ ceramics. Chinese J Lasers 2016, 43: 1002007.

[66] Wilkes J, Hagedorn YC, Meiners W, et al. Additive manufacturing of $\mathrm{ZrO}_{2}-\mathrm{Al}_{2} \mathrm{O}_{3}$ ceramic components by selective laser melting. Rapid Prototyping $J$ 2013, 19: $51-57$.

[67] Manob G, Lu L, Fuh JYH, et al. Porous $\mathrm{Li}_{2} \mathrm{O}$ $\mathrm{Al}_{2} \mathrm{O}_{3} \mathrm{SiO}_{2}$ (LAS) glass-ceramics prepared by selective laser melting and annealing. In: Proceedings of the 27th Annual Cocoa Beach Conference on Advanced Ceramics and Composites: B: Ceramic Engineering and Science Proceedings, 2003, 24: 523-528.

[68] Chen Q, Guillemot G, Gandin CA, et al. Numerical modelling of the impact of energy distribution and Marangoni surface tension on track shape in selective laser melting of ceramic material. Addit Manuf 2018, 21: 713-723.

[69] Liu Q, Song B, Liao HL. Microstructure study on selective laser melting yttria stabilized zirconia ceramic with near IR fiber laser. Rapid Prototyping J 2014, 20: 346-354.

[70] Zhang K, Liu TT, Liao WH, et al. Influence of laser parameters on the surface morphology of slurry-based $\mathrm{Al}_{2} \mathrm{O}_{3}$ parts produced through selective laser melting. Rapid Prototyping J 2018, 24: 333-341.

[71] Shishkovsky I, Yadroitsev I, Bertrand $\mathrm{P}$, et al. Alumina-zirconium ceramics synthesis by selective laser sintering/melting. Appl Surf Sci 2007, 254: 966-970.

[72] Liu HF, Su HJ, Shen ZL, et al. Effect of scanning speed on the solidification process of $\mathrm{Al}_{2} \mathrm{O}_{3} / \mathrm{GdAlO}_{3} / \mathrm{ZrO}_{2}$ eutectic ceramics in a single track by selective laser melting. Ceram Int 2019, 45: 17252-17257.

[73] Ghazanfari A, Li WB, Leu MC, et al. A novel freeform extrusion fabrication process for producing solid ceramic components with uniform layered radiation drying. Addit Manuf 2017, 15: 102-112.

[74] Wei L, Tingting L, Wenhe L, et al. Study and application of selective laser sintering/melting technology of ceramic materials. Bulletin of the Chinese Ceramic Society 2014, 33: 2881-2890, 2896.

[75] Yan X, Xu YX, Wu Y, et al. Effects of heat treatment on metal-ceramic combination of selective-laser-melted cobalt-chromium alloy. J Prosthet Dent 2018, 120: 319.

[76] Guan JR, Wang QP, Zhang XW, et al. Selective laser melting of yttria-stabilized zirconia. Mater Res Express 2018, 6: 015402.

[77] Wang YY, Wang ZY, Liu SH, et al. Additive manufacturing of silica ceramics from aqueous acrylamide based suspension. Ceram Int 2019, 45: 21328-21332.

[78] Liang D, Ru-Jie HE, Fang DN. Development of additive manufacturing of ceramics. Adv Ceram 2017, 38: 231-247.

[79] Wang XF, Schmidt F, Hanaor D, et al. Additive manufacturing of ceramics from preceramic polymers: A versatile stereolithographic approach assisted by thiol-ene click chemistry. Addit Manuf 2019, 27: 80-90.

[80] Melchels FPW, Feijen J, Grijpma DW. A review on stereolithography and its applications in biomedical engineering. Biomaterials 2010, 31: 6121-6130.

[81] González-Henríquez CM, Sarabia-Vallejos MA, RodriguezHernandez J. Polymers for additive manufacturing and 4D-printing: Materials, methodologies, and biomedical applications. Prog Polym Sci 2019, 94: 57-116.

[82] Yu XH, Xing RB, Peng ZX, et al. To inhibit coffee ring effect in inkjet printing of light-emitting polymer films by decreasing capillary force. Chinese Chem Lett 2019, 30: 135-138.

[83] Wu ZW, Liu W, Wu HD, et al. Research into the mechanical properties, sintering mechanism and microstructure evolution of $\mathrm{Al}_{2} \mathrm{O}_{3}-\mathrm{ZrO}_{2}$ composites fabricated by a stereolithography-based $3 \mathrm{D}$ printing method. Mater Chem Phys 2018, 207: 1-10.

[84] Fu XS, Zou B, Xing HY, et al. Effect of printing strategies on forming accuracy and mechanical properties of $\mathrm{ZrO}_{2}$ parts fabricated by SLA technology. Ceram Int 2019, 45: 17630-17637.

[85] Varghese G, Moral M, Castro-García M, et al. Fabrication and characterisation of ceramics via low-cost DLP 3D printing. Bol Soc Esp Ceram V 2018, 57: 9-18.

[86] Lian Q, Wu XQ, Li DC, et al. Accurate printing of a zirconia molar crown bridge using three-part auxiliary supports and ceramic mask projection stereolithography. Ceram Int 2019, 45: 18814-18822.

[87] Saurwalt J, Opschoor J, Berkeveld L. Powder metallurgical steel quality by additive manufacturing using VAT polymerisation technology. Petten: ECN, 2017.

[88] Yang F. Ceramics fabrication using rapid prototyping of mask projection stereolithography. $J$ Mech Eng 2017, 53: 138.

[89] Halloran JW, Tomeckova V, Gentry S, et al. Photopolymerization of powder suspensions for shaping ceramics. J Eur Ceram Soc 2011, 31: 2613-2619.

[90] Xing HY, Zou B, Lai QG, et al. Preparation and characterization of $\mathrm{UV}$ curable $\mathrm{Al}_{2} \mathrm{O}_{3}$ suspensions applying for stereolithography $3 \mathrm{D}$ printing ceramic microcomponent. Powder Technol 2018, 338: 153-161.

[91] Chen ZW, Li JJ, Liu CB, et al. Preparation of high solid loading and low viscosity ceramic slurries for photopolymerization-based 3D printing. Ceram Int 2019, 45: 11549-11557.

[92] Wu HD, Cheng YL, Liu W, et al. Effect of the particle size and the debinding process on the density of alumina 
ceramics fabricated by $3 \mathrm{D}$ printing based on stereolithography. Ceram Int 2016, 42: 17290-17294.

[93] German RM, Park SJ. Mathematical Relations in Particulate Materials Processing. Hoboken, NJ, USA: John Wiley \& Sons, Inc., 2008.

[94] Bae CJ, Halloran JW. Concentrated suspension-based additive manufacturing - Viscosity, packing density, and segregation. J Eur Ceram Soc 2019, 39: 4299-4306.

[95] Dehurtevent M, Robberecht L, Hornez JC, et al. Stereolithography: A new method for processing dental ceramics by additive computer-aided manufacturing. Dent Mater 2017, 33: 477-485.

[96] Song SY, Park MS, Lee D, et al. Optimization and characterization of high-viscosity $\mathrm{ZrO}_{2}$ ceramic nanocomposite resins for supportless stereolithography. Mater Des 2019, 180: 107960.

[97] He RJ, Ding GJ, Zhang KQ, et al. Fabrication of SiC ceramic architectures using stereolithography combined with precursor infiltration and pyrolysis. Ceram Int 2019, 45: 14006-14014.

[98] Zhou WZ, Li DC, Wang H. A novel aqueous ceramic suspension for ceramic stereolithography. Rapid Prototyping J 2010, 16: 29-35.

[99] Wang WJ, Qian C, Hu ML, et al. Optimisation of scanning parameters in stereolithography for dental zirconia ceramic fabrication. Adv Appl Ceram 2020, 119: 244-251.

[100] Member GTEE. Appendix A: Orthogonal arrays and linear graphs: Tools for quality engineering. In: Taguchi's Quality Engineering Handbook. Hoboken, NJ, USA: John Wiley \& Sons, Inc., 2007: 1523-1597.

[101] Xing HY, Zou B, Li SS, et al. Study on surface quality, precision and mechanical properties of 3D printed $\mathrm{ZrO}_{2}$ ceramic components by laser scanning stereolithography. Ceram Int 2017, 43: 16340-16347.

[102] Osman RB, van der Veen AJ, Huiberts D, et al. 3D-printing zirconia implants; a dream or a reality? An in-vitro study evaluating the dimensional accuracy, surface topography and mechanical properties of printed zirconia implant and discs. J Mech Behav Biomed Mater 2017, 75 : 521-528.

[103] Li H, Liu YS, Liu YS, et al. Effect of sintering temperature in argon atmosphere on microstructure and properties of 3D printed alumina ceramic cores. J Adv Ceram 2020, 9: 220-231.

[104] Deckers J, Vleugels J, Kruthl JP. Additive manufacturing of ceramics: A review. J Ceram Sci Technol 2014, 5: 245-260.

[105] Padolskytè V, Gailevičius D, Jonušauskas L, et al. 3D opto-structuring of ceramics at nanoscale. In: Proceedings of the SPIE 10675, 3D Printed Optics and Additive Photonic Manufacturing, 2018: 106750U.

[106] Zhang DW, Peng E, Borayek R, et al. Controllable ceramic green-body configuration for complex ceramic architectures with fine features. Adv Funct Mater 2019, 29: 1807082.
[107] Liska R, Schuster M, Inführ R, et al. Photopolymers for rapid prototyping. J Coat Technol Res 2007, 4: 505-510.

[108] Baumgartner S, Gmeiner R, Schönherr JA, et al. Stereolithography-based additive manufacturing of lithium disilicate glass ceramic for dental applications. Mater Sci Eng C 2020, 116: 111180.

[109] Zeng YS, Jiang LM, Sun YZ, et al. 3D-printing piezoelectric composite with honeycomb structure for ultrasonic devices. Micromachines 2020, 11: 713.

[110] Song X, Chen ZY, Lei LW, et al. Piezoelectric component fabrication using projection-based stereolithography of barium titanate ceramic suspensions. Rapid Prototyping $J$ 2017, 23: 44-53.

[111] Wang W, Sun JX, Guo BB, et al. Fabrication of piezoelectric nano-ceramics via stereolithography of low viscous and non-aqueous suspensions. J Eur Ceram Soc 2020, 40: 682-688.

[112] Cheng J, Chen Y, Wu JW, et al. 3D printing of $\mathrm{BaTiO}_{3}$ piezoelectric ceramics for a focused ultrasonic array. Sensors 2019, 19: 4078.

[113] Chen ZY, Song X, Lei LW, et al. 3D printing of piezoelectric element for energy focusing and ultrasonic sensing. Nano Energy 2016, 27: 78-86.

[114] Ruiz-Morales JC, Hernández-Rodríguez EM, Acosta-Mora $\mathrm{P}$, et al. Prospective use of the 3D printing technology for the microstructural engineering of Solid Oxide Fuel Cell components. Bol Soc Esp Ceram Vidr 2014, 53: 213-216.

[115] Sardar S, Kale G, Ghadiri M. Influence of processing conditions on the ionic conductivity of holmium zirconate $\left(\mathrm{Ho}_{2} \mathrm{Zr}_{2} \mathrm{O}_{7}\right)$. Ceram Int 2020, 46: 11508-11514.

[116] Wei LY, Zhang JJ, Yu FY, et al. A novel fabrication of yttria-stabilized-zirconia dense electrolyte for solid oxide fuel cells by 3D printing technique. Int J Hydrogen Energ 2019, 44: 6182-6191.

[117] Xing BH, Cao CR, Zhao WM, et al. Dense 8 mol\% yttriastabilized zirconia electrolyte by DLP stereolithography. $J$ Eur Ceram Soc 2020, 40: 1418-1423.

[118] Xing BH, Yao YX, Meng X, et al. Self-supported yttria-stabilized zirconia ripple-shaped electrolyte for solid oxide fuel cells application by digital light processing three-dimension printing. Scripta Mater 2020, 181: 62-65.

[119] Zhang J, Lenser C, Menzler NH, et al. Comparison of solid oxide fuel cell (SOFC) electrolyte materials for operation at $500{ }^{\circ} \mathrm{C}$. Solid State Ionics 2020, 344: 115138.

[120] Seo H, Iwai H, Kishimoto M, et al. Microextrusion printing for increasing electrode-electrolyte interface in anode-supported solid oxide fuel cells. J Power Sources 2020, 450: 227682.

[121] Pesce A, Hornés A, Núñez M, et al. 3D printing the next generation of enhanced solid oxide fuel and electrolysis cells. J Mater Chem A 2020, 8: 16926-16932.

[122] Masciandaro S, Torrell M, Leone P, et al. Threedimensional printed yttria-stabilized zirconia selfsupported electrolytes for solid oxide fuel cell applications. 
J Eur Ceram Soc 2019, 39: 9-16.

[123] Zhou SX, Mei H, Chang P, et al. Molecule editable 3D printed polymer-derived ceramics. Coordin Chem Rev 2020, 422: 213486.

[124] Saroia J, Wang YN, Wei QH, et al. A review on 3D printed matrix polymer composites: Its potential and future challenges. Int J Adv Manuf Technol 2020, 106: 16951721.

[125] Li XB, Zhang JX, Duan YS, et al. Rheology and curability characterization of photosensitive slurries for 3D printing of $\mathrm{Si}_{3} \mathrm{~N}_{4}$ ceramics. Appl Sci 2020, 10: 6438 .

[126] Gyak KW, Vishwakarma NK, Hwang YH, et al. 3D-printed monolithic SiCN ceramic microreactors from a photocurable preceramic resin for the high temperature ammonia cracking process. React Chem Eng 2019, 4: 1393-1399.

[127] Schmidt J, Altun AA, Schwentenwein M, et al. Complex mullite structures fabricated via digital light processing of a preceramic polysiloxane with active alumina fillers. $J$ Eur Ceram Soc 2019, 39: 1336-1343.

[128] He M, Zhao Y, Liu Y, et al. A 3D printable self-healing composite conductive polymer for sensitive temperature detection. Chinese Chem Lett 2020, 31: 826-830.

[129] Lu ZL, Cao JW, Song ZQ, et al. Research progress of ceramic matrix composite parts based on additive manufacturing technology. Virtual Phys Prototyp 2019, 14: 333-348.

[130] Peng E, Zhang DW, Ding J. Ceramic robocasting: Recent achievements, potential, and future developments. $A d v$ Mater 2018, 30: e1802404.

[131] Ji H, Zhang X, Pei W, et al. Research progress in ceramic $3 \mathrm{D}$ printing technology and material development. Journal of Materials Engineering 2018, 46: 19-28.

[132] Li Y, Si Y, Xiong X, et al. Research and progress on three dimensional printing of ceramic materials. Journal of the Chinese Ceramic Society 2017, 45: 793-805.

[133] Revelo CF, Colorado HA. 3D printing of kaolinite clay ceramics using the Direct Ink Writing (DIW) technique. Ceram Int 2018, 44: 5673-5682.

[134] Guo R, Qi H, Chen Y, et al. Reverse microemulsion region and composition optimization of the $\mathrm{AEO}_{9} /$ alcohol/alkane/ water system. Mater Res Bull 2003, 38: 1501-1507.

[135] Chen T, Sun AH, Chu CY, et al. Rheological behavior of titania ink and mechanical properties of titania ceramic structures by $3 \mathrm{D}$ direct ink writing using high solid loading titania ceramic ink. J Alloys Compd 2019, 783: 321-328.

[136] Eqtesadi S, Motealleh A, Perera FH, et al. Fabricating geometrically-complex $\mathrm{B}_{4} \mathrm{C}$ ceramic components by robocasting and pressureless spark plasma sintering. Scripta Mater 2018, 145: 14-18.

[137] Chen ZW, Li ZY, Li JJ, et al. 3D printing of ceramics: A review. J Eur Ceram Soc 2019, 39: 661-687.

[138] Cai KP, Román-Manso B, Smay JE, et al. Geometrically complex silicon carbide structures fabricated by robocasting. J Am Ceram Soc 2012, 95: 2660-2666.

[139] Zhao Z, Zhou GX, Yang ZH, et al. Direct ink writing of continuous $\mathrm{SiO}_{2}$ fiber reinforced wave-transparent ceramics. J Adv Ceram 2020, 9: 403-412.

[140] Li YY, Li LT, Li B. Direct ink writing of 3-3 piezoelectric composite. J Alloys Compd 2015, 620: 125-128.

[141] Rueschhoff L, Costakis W, Michie M, et al. Additive manufacturing of dense ceramic parts via direct ink writing of aqueous alumina suspensions. Int J Appl Ceram Technol 2016, 13: 821-830.

[142] Guo RS, Qi HT, Yang ZF, et al. Preparation and properties of the $\mathrm{AEO}_{9} /$ alcohol/alkane/water reverse microemulsion ceramic inks. Ceram Int 2004, 30: 2259-2267.

[143] Jin HZ, Yang ZH, Cai DL, et al. 3D printing of porous $\mathrm{Si}_{2} \mathrm{~N}_{2} \mathrm{O}$ ceramics based on strengthened green bodies fabricated via strong colloidal gel. Mater Des 2020, 185: 108220.

[144] Yang LL, Zeng XJ, Ditta A, et al. Preliminary 3D printing of large inclined-shaped alumina ceramic parts by direct ink writing. J Adv Ceram 2020, 9: 312-319.

[145] Mohamed OA, Masood SH, Bhowmik JL. Analysis of wear behavior of additively manufactured PC-ABS parts. Mater Lett 2018, 230: 261-265.

[146] Buj-Corral I, Dominguez-Fernandez A, Gomez-Gejo A. Effect of printing parameters on dimensional error and surface roughness obtained in direct ink writing (DIW) processes. Materials 2020, 13: 2157.

[147] Rosental T, Magdassi S. A new approach to 3D printing dense ceramics by ceramic precursor binders. Adv Eng Mater 2019, 21: 1900604.

[148] Guo R, Qi H, Guo D, et al. Preparation of high concentration ceramic inks for forming by jet-printing. $J$ Eur Ceram Soc 2003, 23: 115-122.

Open Access This article is licensed under a Creative Commons Attribution 4.0 International License, which permits use, sharing, adaptation, distribution and reproduction in any medium or format, as long as you give appropriate credit to the original author(s) and the source, provide a link to the Creative Commons licence, and indicate if changes were made.

The images or other third party material in this article are included in the article's Creative Commons licence, unless indicated otherwise in a credit line to the material. If material is not included in the article's Creative Commons licence and your intended use is not permitted by statutory regulation or exceeds the permitted use, you will need to obtain permission directly from the copyright holder.

To view a copy of this licence, visit http://creativecommons.org/licenses/by/4.0/. 